\title{
Protein glycosylation in head and neck cancers: From diagnosis to treatment
}

Mohammad Rasheduzzaman ${ }^{1,2}$, Arutha Kulasinghe ${ }^{1,2}$, Riccardo Dolcetti ${ }^{2,3}$, Liz Kenny, ${ }^{4}$, Newell W. Johnson $^{5,6}$, Daniel Kolarich ${ }^{7,8 *}$, Chamindie Punyadeera ${ }^{1,2} *$

1. Saliva and Liquid Biopsy Translational Laboratory, The School of Biomedical Sciences, Institute of Health and Biomedical Innovation, Queensland University of Technology, Kelvin Grove, QLD, Australia.

2. Translational Research Institute, Woolloongabba, QLD, Australia.

3. The University of Queensland Diamantina Institute, 37 Kent Street Woolloongabba, QLD, 4102, Australia.

4. Department of Radiation Oncology, Cancer Care Services, Royal Brisbane and Women's Hospital, Joyce Tweddell Building, Herston, QLD, 4029, Australia.

5. Menzies Health Institute Queensland, Griffith University, Southport, Queensland, Australia

6. Faculty of Dentistry, Oral and Craniofacial Sciences, King's College, London

7. Institute for Glycomics, Griffith University, Gold Coast, QLD, Australia

8. ARC Centre of Excellence for Nanoscale BioPhotonics, Griffith University, QLD, Australia

*Corresponding Authors

Associate Professor Chamindie Punyadeera

Address: Saliva and liquid biopsy translational research team, The School of Biomedical Sciences, Room 603D, Institute of Health and Biomedical Innovations, Queensland University of Technology, 60 Musk Avenue, Kelvin Grove, QLD 4059, Australia.

Telephone: +61731380830

Fax: +61731386030

Email: chamindie.punyadeera@qut.edu.au

Associate Professor Daniel Kolarich

Institute for Glycomics, Griffith University, Gold Coast Campus, 4222 Southport, Queensland, Australia

Tel.: +61-7-5552 7026

Email: d.kolarich@griffith.edu.au

Keywords: Head and neck cancers, protein glycosylation, liquid biopsy, cancer metastasis, biomarkers 


\begin{abstract}
Glycosylation is the most common post-translational modification (PTM) of proteins. Cells of a malignant tumour frequently display altered glycosylation of cell surface proteins. These are common in cancers of the head and neck, most of which are squamous cell carcinomas (HNSCC). Many cell properties and functions are affected, including proliferation and movement, thus increasing the propensity to metastasise. HNSCC represents the sixth most frequent malignancy worldwide. These neoplasms, which arise from the mucous membranes of the various anatomical subsites of the upper aero-digestive tract, are heterogeneous in terms of aetiology and clinico-pathologic features. With current treatments, only about $50 \%$ of HNSCC patients survive beyond 5 -years. Therefore, there is the pressing need to dissect NHSCC heterogeneity to inform treatment choices. In particular, reliable biomarkers of predictive and prognostic value are eagerly needed. This review describes the current state of the art and bio-pathological meaning of glycosylation signatures associated with HNSCC and explores the possible role of tumour specific glycoproteins as potential biomarkers and attractive therapeutic targets. We have also compiled data relating to altered glycosylation and the nature of glycoproteins as tools for the identification of circulating tumour cells (CTCs) in the new era of liquid biopsy.
\end{abstract}

\begin{abstract}
Abbreviations
AFP- $\alpha$-fetoprotein; CEACAM6- Carcinoembryonic antigen-related cell adhesion molecule 6; OSCCOral squamous cell carcinoma; C1GALT1- Core 1 ß1,3-galactosyltransferase; CTHRC1- Collagen triple helix repeat containing protein1; DPAGT1- Dolichyl-Phosphate $\mathrm{N}$ -
\end{abstract} Acetylglucosaminephosphotransferase 1; ESOSCC- Early stage oral squamous cell carcinoma; TAMUC1- Tumour-associated Mucin 1; EGFR- Epidermal growth factor receptor; FUT3Fucosyltransferase 3; GalNAc-T3- N-acetylgalactosaminyltransferase 3; GALNT6- polypeptide Nacetylgalactosaminyltransferase 6; GnT-V - $\beta 1-6-N$-acetylglucosaminyltransferase V; GlcNAc- Nacetylglucosamine; ST3GAL3- ST3 $\beta$-galactoside $\alpha 2$-3-sialyltransferase 3; HNC- Head and Neck Cancer; HNSCC- head and neck squamous cell carcinoma; MGAT5-N-acetylglucosaminyltransferase 5; OPC- oropharyngeal cancers; PSA- prostate specific antigen; PTM- post translational modification; ST36GAL3- ST3 $\beta$-galactoside $\alpha 2$-6-sialyltransferase 3; Tn- T nouvelle antigen 


\section{Introduction}

There are over half a million new cases of head and neck cancers diagnosed globally each year [1]. The majority of these originate from the stratified squamous epithelia of the mucous membranes lining the lip, oral cavity, oropharynx, hypopharynx, larynx, nasopharynx and facial sinuses and are, histopathologically, squamous cell carcinomas (HNSCC), of various subtypes. Their aetiology and risk factors vary by site and subsite. HNSCCs are the sixth most common form of malignancy and are responsible for $3-4 \%$ of cancer-related deaths globally [2]. Furthermore, $50 \%$ of patients with HNSCC succumb to their disease within 5 years of diagnosis. Therefore, early detection, monitoring for treatment response and early detection of recurrence are important clinical needs [3, 4]. Traditional risk factors for HNSCC include smoking tobacco, chewing of smokeless tobacco, areca (betel) nut chewing, heavy alcohol use and, increasingly, infection with certain high-risk (hr) human papillomavirus (HPV) genotypes [5]. The most significant hr types, HPV-16 and -18 are small, double-stranded, circular DNA viruses that are responsible for a subset of HNSCC, mainly originating in the oropharynx (oropharyngeal cancers, OPC). HPV is the major culprit for the rising global incidence of OPC [6]. HPV positive OPC patients have relatively better clinical outcomes than patients with HPV negative [7] as they respond well to radiation treatment, possibly due to higher sensitivity to radiation and/or an increased anti-tumour immunity $[8,9]$.

Current diagnostic modalities for HNSCC include a combination of clinical examination, XRadiography, and CT/PET/MRI scans [10]. Tissue biopsy remains the gold standard, but apart from the lip and mouth, affected sites are difficult to access [11-13]. Occult primary tumours are also a clinical problem. Therefore, complementary methodologies are needed for diagnosis and monitoring. There is a need for biomarkers to monitor treatment response, metastasis and recurrence. Liquid biopsies can play an important role in addressing these needs. Liquid biopsies include analysis of CTCs and/or their products (circulating tumour DNA, cell-free miRNA, and extracellular vesicles: EV) in blood or other body fluids - saliva in the case of HNSCC [14]. Liquid biopsies are simple, minimally invasive procedures that can capture tumour heterogeneity in real-time and play an important role when there is no tumour tissue available: these are multiclonal neoplasms; different clones shed at different times and rates and it may be possible to track these using repeated peripheral blood samples $[15,16]$.

A cancer biomarker is regarded as a substance or process that can inform and discriminate a specific cancer type and may provide predictive information of the treatment response. Such biomarkers may include mutated DNAs and RNAs, secreted proteins, cell death and proliferation clues, as well as small metabolites such as glucose or cholesterol [17]. The vast majority of current protein-based cancer biomarkers (such as prostate specific antigen for prostate cancer or CA-125 for ovarian cancer) are all glycoproteins [18], which undergo a number of post-translational modification (PTM) steps where specific sugar molecules (=glycans) are attached [19]. Approximately half of all proteins expressed in a cell, in particular within the plasma membrane cell surface, are glycoproteins that are crucial for 
regulating cell physiology and pathology. Many cancer cells change their cell surface "glyco-coating", which affects the harmony of protein arrangements and interactions, the biological activity of cells and in consequence may contribute to oncogenesis [20]. This review provides a concise overview on the literature on HNSCC associated aspects of protein glycosylation-

\subsection{A short introduction to protein glycosylation}

Glycans are ubiquitous structures present in all living organisms and essential for life, as they are involved in coordinating multiple biological processes [21]. Glycosylation is a tightly regulated enzymatic process requiring several hundred of different, individual enzymes that modify proteins and regulate key biological functions [22-24]. Glycoconjugates govern a number of processes in the case of stratified squamous epithelia, binding keratinocytes to each other and to the basement membrane, linking stromal cells to extracellular matrix, and modulating cellular differentiation [20]. In HNSCC, as in all carcinoma, once transformed, keratinocytes invade the connective tissue, where glycoconjugates again play an important role in their interaction with stromal and immune cells. Most intracellular proteins on a secretory pathway are glycosylated to a variable extent during their passage through the ER and Golgi: these include secreted proteins, surface receptors and ligands, and organelleresident proteins. Glycosphingolipids and proteoglycans are other glycoconjugates frequently modified during carcinogenesis [25]. Protein glycosylation is characterized by several glycosidic linkages, including $\mathrm{N}$-, $\mathrm{O}$ - (Figure 1) and $\mathrm{C}$-linked glycosylation, glypication (GPI anchor attachment), and phosphoglycosylation. This range of different $N$ - and $O$-glycoconjugates fulfils many functions such as supporting structural components to the cell wall and ECM, promoting protein stability and solubility, cell signalling pathways and recognition, to name a few [20,26]. 


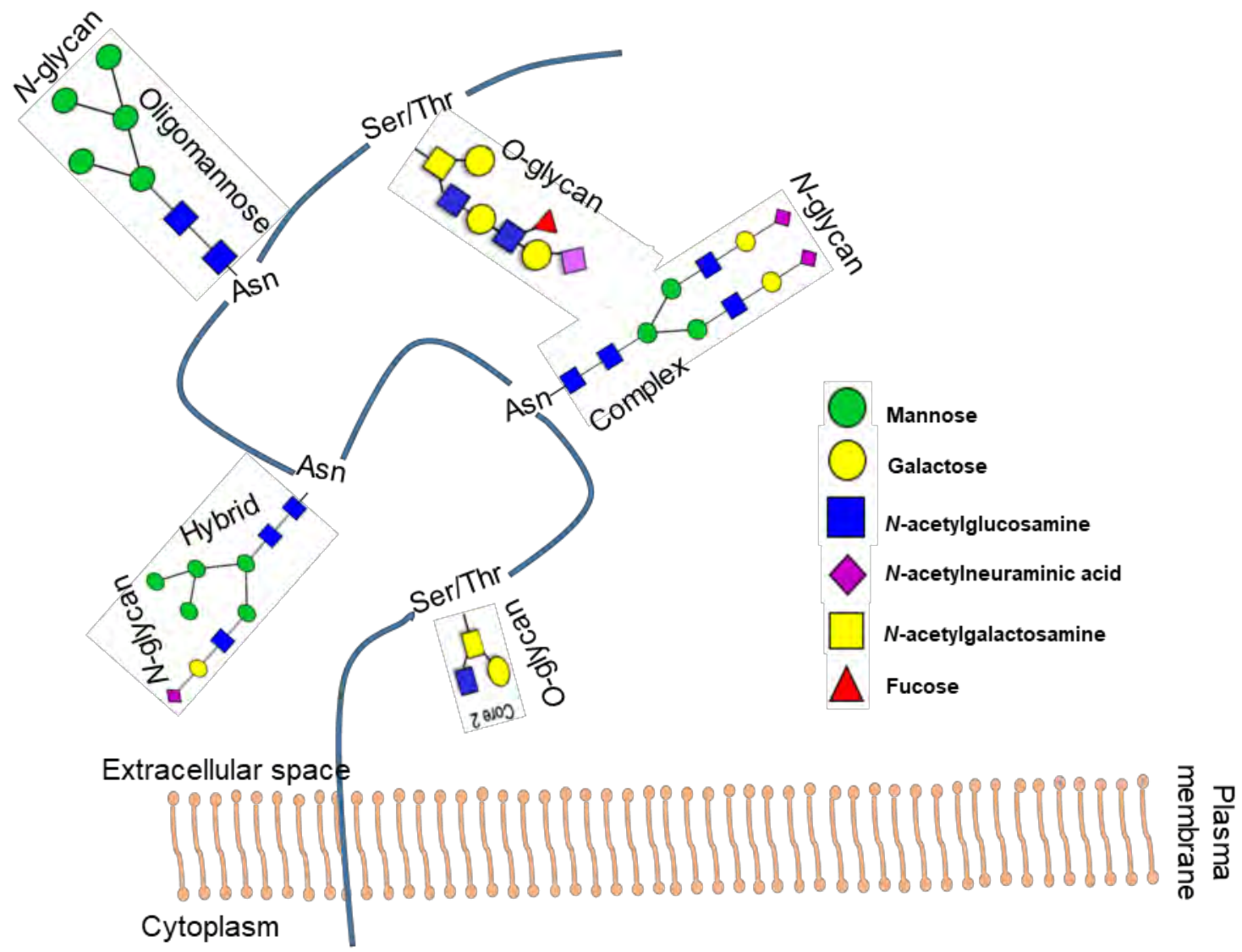

Figure 1: Representative $\mathrm{N}$-and $\mathrm{O}$-glycoconjugates present in human cells. $\mathrm{N}$-glycans are attached to asparagine residues and share common core regions that can be further modified into oligomannose, hybrid and complex structures. Mucin type $O$-glycans are initiated by $N$-acetylgalactosamine $O$-linked to Ser/Thr residues of glycoproteins. Depicted structures are exemplary and do not represent naturally present glyco-heterogeneity.

\section{$\underline{N \text {-glycosylation }}$}

$N$-glycosylation is both a co- and a post-translational modification. " $N$ "-glycosylation refers to the fact that these glycans are covalently linked to the protein via the carboxamido nitrogen on asparagine (Asn) residues. During translation of the mRNA chain into the ER, an oligomannose precursor is attached to a glycoprotein on specific Asn residues that are part of the common $N$-glycosylation sequon -Asn-X$\mathrm{Ser} / \mathrm{Thr} / \mathrm{Cys}$ (X $\neq \mathrm{Pro}$ ) [27]. The 14-sugar oligosaccharide precursor consists of mannose (Man), $N$ acetylglucosamine (GlcNAc) and glucose monosaccharides that are first pre-assembled by stepwise synthesis in the ER, utilizing several specific glycosyltransferases. The oligosaccharyltransferase (OST) complex then transfers this structure onto the nascent polypeptide chain that is translocated into the ER. Once attached, $\mathrm{N}$-glycans support protein folding before they undergo further post-translational processing in the Golgi apparatus, where smaller forms of oligomannose type $N$-glycans as well as complex and hybrid type structures are formed (Figure 2). The various glycosyltransferases that produce 
the different forms of $\mathrm{N}$-glycans such as sialylated, fucosylated or extended ones are sitting within the various Golgi compartments. Based on these varieties of further processing, $N$-glycans can be classified into four major classes, while all classes share a common core pentasaccharide ( $\left.\mathrm{Man}_{3} \mathrm{GlcNAc}_{2}\right)$, except glycans of the paucimannose type. These classes are: (a) paucimannose type, where $N$-glycans can be trimmed down again until the Asn-linked GlcNAc; (b) oligomannose type, which reflect different forms of the initial precursor $\mathrm{N}$-glycans that have not experienced further processing except mannosidase digestion; (c) hybrid type, which are a mixture of oligomannose glycans and complex types and (d) complex type, where the core pentasaccharide is extended with different antennae that can be capped with different glyco-epitopes such as sialic acid, fucose or galactose, or $N$-acetylgalactosamine [28, 29] (Figure 2). With the exception of oligomannose type $\mathrm{N}$-glycans, all other types can also occur in a bisected form (Figure 2). $\mathrm{N}$-glycosylation is crucial for the function, localisation and interaction of their individual protein carriers [30]. 
A

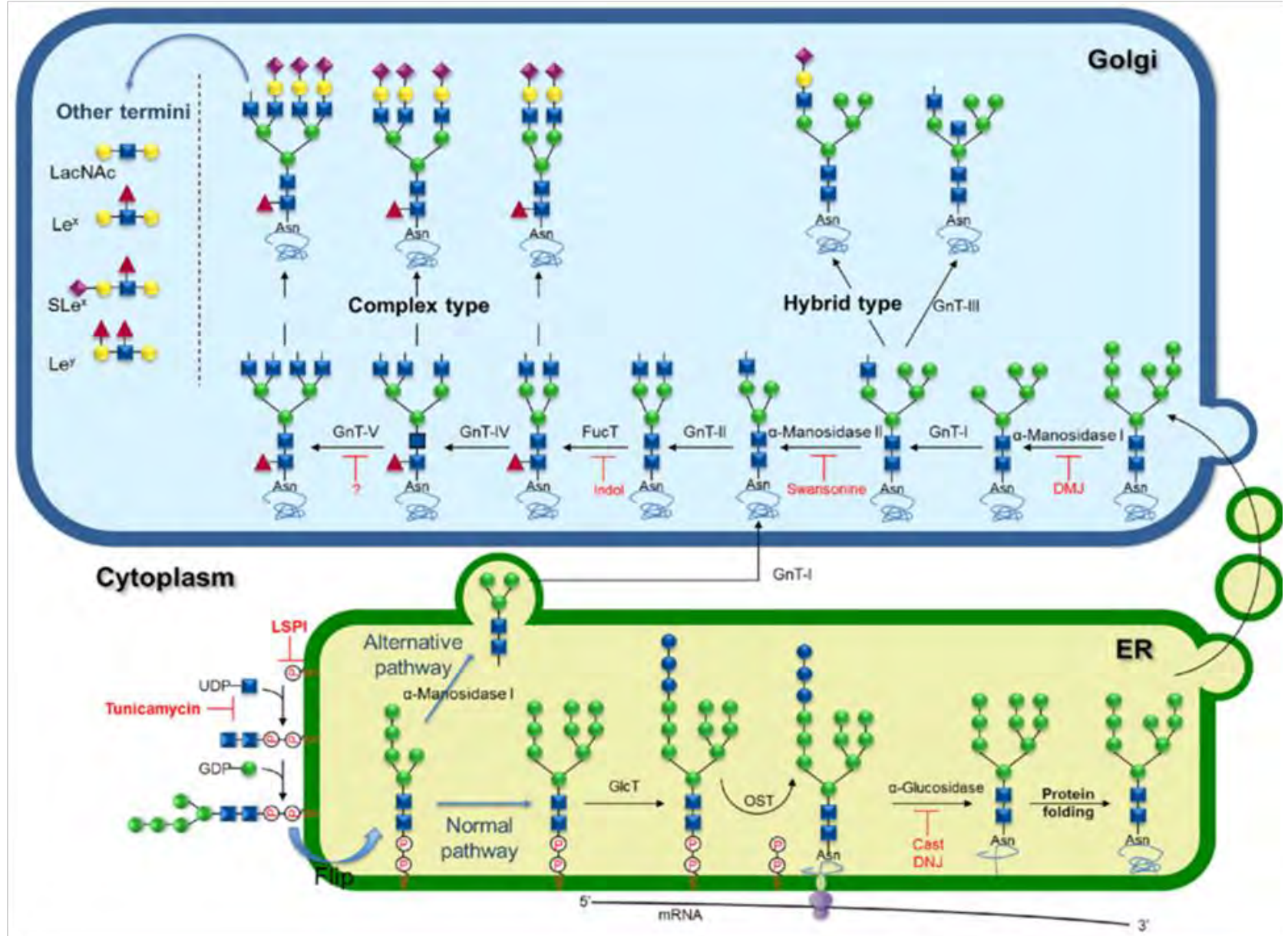

B

$\mathrm{N}$-glycan types
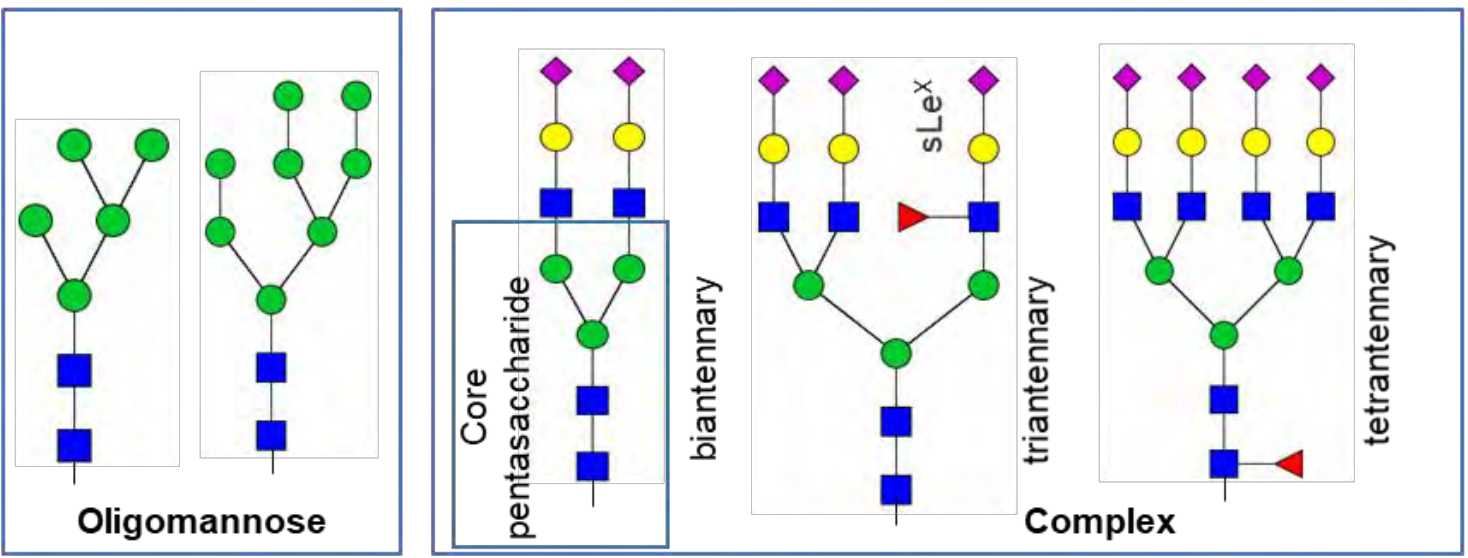

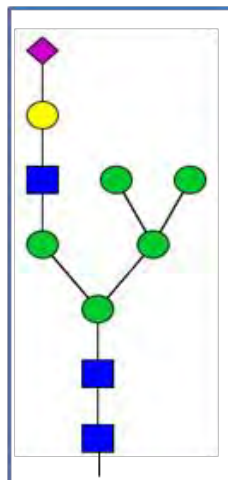

Hybrid

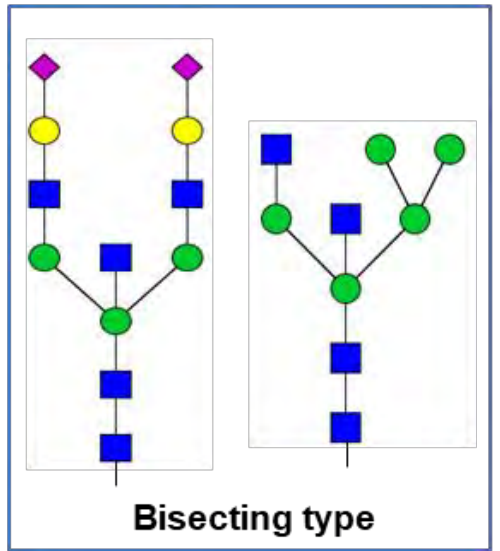

Bisecting type

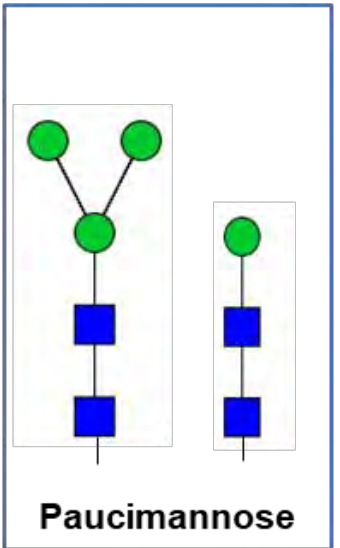

Mannose

$\bigcirc$ Galactose

$N$-acetylglucosamine

N-acetylneuraminic acid

$\mathrm{N}$-acetylgalactosamine

$\triangle$ Fucose 
Figure 2: Schematic presentation of biosynthesis and processing of $\mathrm{N}$-glycosylation.

A. Formation of the $\mathrm{N}$-glycan precursor starts at the cytoplasmic face of the ER membrane with the stepwise assembly of a 7-residue oligosaccharide precursor linked to the lipid dolichol-phosphate. This dolichol-linked oligosaccharide chain is now flipped into the lumen of the ER, where the assembly of the $\mathrm{Glc}_{3} \mathrm{Man}_{9} \mathrm{GlcNAc}_{2}$ dolichol-phosphate precursor is finished. This 14-mer oligosaccharide is then used by the oligosaccharyltransferase (OST) and attached onto an Asn side-chain of the growing polypeptide chain if the Asn is part of the consensus sequence Asn-X-Ser/Thr/Cys (XғPro), where it then regulates proper protein folding. Following successful protein folding, specific glucosidases and mannosidases trim the precursor into the $\mathrm{Man}_{8} \mathrm{GlcNAc}_{2}$ oligomannose structure before the glycoprotein is transported into the cis-Golgi. There $N$-glycans destined to become complex or hybrid type glycans are further trimmed by mannosidases before they are re-built into complex/hybrid types. $\mathrm{N}$ glycosylation is accomplished by a complex interplay between different glycosidases (glycan-

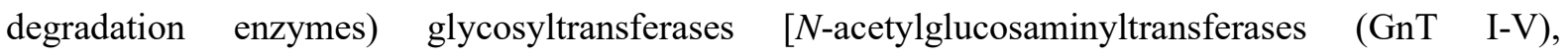
fucosyltransferases (FUTs), various galactosyl- (GALTs) and sialyltransferases (STs)]. During sialylation, sialic acid is attached to the oligosaccharides as the terminal monosaccharide. In Eukaryotes two forms of sialic acid are known: $\mathrm{N}$-acetylneuraminic acid (Neu5Ac) and $\mathrm{N}$ glycolylneuraminic acid (Neu5Gc), though the latter is absent in humans due to the absence of machinery to synthesise Neu5Gc. Neu5Gc, however, has sometimes been reported in normal human tissues/body fluids (possibly due to incorporation from dietary sources). While some studies have indicated that malignant human tissues can exhibit increased NeuGc levels, this is an ongoing matter or research. Fucosylation is regulated by FUTs consisting of 13 members including FUT1 to 11, the GDP-fucose biosynthesis pathway and fucose transporter. FUTs catalyse the attachment of fucose onto $N$-, $O$-, and lipid-linked glycans through an $\alpha 1-2$ - (by FUT1 and 2), $\alpha 1-3-$ (by FUT3 to 7 and FUT9 to 11), $\alpha 1-4$ - (by FUT3 and 5), or $\alpha 1-6-$ (by FUT8) linkages. Fucose attached to the antenna lactosamine epitopes generates Lewis $\mathrm{a} / \mathrm{b}, \mathrm{x} / \mathrm{y}, \mathrm{ABO}$ blood group antigens and further attachment of sialic acid generates sialyl Lewis a and $\mathrm{x}$ epitopes. A number of inhibitors are available that interfere at different points in this biosynthetic pathway [tunicamycin, castanospermine (Cast), 1deoxynojirimycin (DNJ), 1-deoxymannojirimycin (DMJ), swainsonine, and indolizidine (Indol)]. Figure modified and reproduced from Vasconcelos-dos-Santos et al. with permission [31].

B. Representative examples for the major $N$-glycan classes. Starting from the oligomannose precursors, the hybrid and various complex type $N$-glycans are formed, which can also occur in a bisected form. The enzyme $\beta 1,4-N$-acetylglucosaminyltransferase III (GnT-III) catalyzes the addition of a bisecting $N$-acetylglucosamine (GlcNAc) to $N$-glycans. Paucimannose type $N$-glycans are formed by $\mathrm{N}$-glycans being trimming down again (usually in lysosomal compartments) and range from a single GlcNAc up to the core pentasaccharide [32]. 


\section{$\underline{O \text {-glycosylation }}$}

$O$-glycosylation is an essential component of mucins found in mucous secretions, but also occurs on a large variety of non-mucin glycoproteins. The name $O$-glycans is derived from the fact that these glycans are attached to the protein via the oxygen atom of hydroxyl side chains of serine and threonine residues. $O$-glycans are usually added in a stepwise process on folded proteins within the Golgi apparatus. Mucin type $O$-glycosylation (also known as $O$-GalNAc glycans) is initiated by 20 different polypeptide GalNAc-tranferases (GALNTs) encoded in the human genome [33]. This first step results in the formation of the Tn antigen, which can then be further modified into different $O$-glycan structures (Figure 3A) [34]. Additionally, a number of different forms of $O$-glycosylation can be catalysed, which differ in the initiating monosaccharide, their protein substrate and the modified amino acids that further contribute to a large variety of $O$-glycosylations, such as those found on collagen where hydroxylysine and hydroxyproline residues, respectively, can be glycosylated. These are distinctly different and often frequently protein-specific compared to mucin-type $O$-glycans, which usually are considered the most widely occurring type of $O$-glycosylation [33].

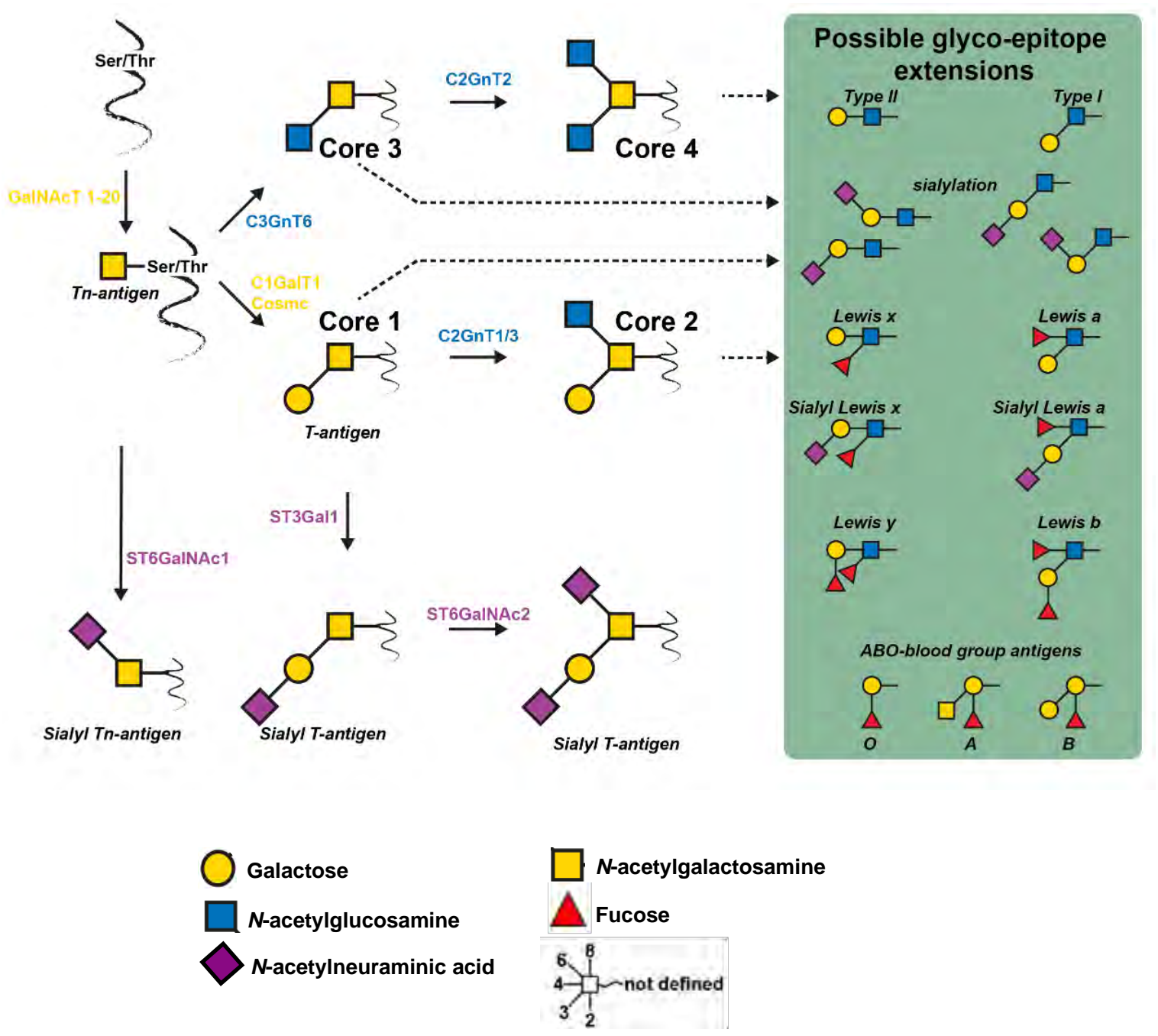


Figure 3: Biosynthesis pathway schematics of mucin type $O$-glycosylation. $O$-glycosylation commences with an attachment of one GalNAc by a GALNT to a serine/threonine (S/T) side chain of an already folded protein or protein complex to form the Tn antigen. This Tn antigen can then be further modified into core 1 type $O$-glycans by the enzyme C1GALT1 to form the T-antigen. The molecular chaperon COSMC is also required for proper activity in the Golgi. Tn and $\mathrm{T}$ antigen can be further elongated to form sialyl Tn-antigen and sialyl T-antigen, respectively, by the action of sialyltransferase (ST6GALNAc1-2 and ST3GAL1). The enzyme $N$-acetylglucosaminyltransferase (C2GnT1/3) generates core 2 type $O$-glycans by adding a GlcNAc in $\beta 1-6$ linkage to the T-antigen. The enzyme $\beta 1-$ $3 \mathrm{~N}$-acetylglucosaminyltransferase 6 is responsible for the formation of core 3 type $O$-glycans from the Tn-antigen. Core 4 is formed by the addition of one GlcNAc to a core 3 type $O$-glycan, catalysed by $\mathrm{C} 2 \mathrm{GnT} 2$ transferase. Sequential action of GalT and GlcNAcT gives rise to polylactosamine chains. The ends of the chains are capped with monosaccharides such as fucose and sialic acid, thus, terminal structures make up important Lewis antigens (blood group determinants).

\subsection{Glycans and glycosyltransferases in the cancer microenvironment}

\section{Glycosylation in the tumour microenvironment}

Neoplastic transformation is associated with changes in cell glycosylation. In consequence, signalling pathways involving glycoproteins and/or glycolipids are functionally affected, including enhanced or suppressed proliferation and invasion of malignant cells, cell-matrix interactions, angiogenesis, metastasis and immune modulation [35]. Alteration or overexpression of glycans is commonly observed during carcinogenesis [36]. Altered glycosylation features include: aberrant expression and glycosylation of mucins; unusual branching of $\mathrm{N}$-glycans; neo-synthesis and incomplete synthesis; increased overall sialic acid content or enhanced expression of sialic acids attached in different linkages to proteins and glycolipids; or increased fucosylation [37, 38].

Glycosylation plays an important role in regulating cell adhesion and in the initiation of malignant cell disassociation and invasion. An enzyme DPAGT1, encoded by DPAGT1 gene, begins the synthesis of the lipid-linked oligosaccharide precursor for protein $\mathrm{N}$-glycosylation in the endoplasmic reticulum. DPAGT1 controls the extent of $N$-glycosylation, hence high DPAGT1 expression is associated with cell proliferation while downregulation characterizes growth-arrest with mature adherens junctions. Alterations of DPAGT1 disrupt the protein E-cadherin-mediated adherens junctions that subsequently leads to mislocalization and dysfunction of E-cadherin, promoting a more migratory cell phenotype, contributing to tumour progression $[39,40]$. The alteration of epithelial cadherin (E-cadherin) carrying $\beta 1-6-N$-acetylglucosamine ( $\beta 1-6$ GlcNAc) modify $N$-glycans (the product of GnT-V activity), as such interrupts cell adhesion and assists cell invasion [41]. Modified $O$-glycosylation, such as over expression of tumour associated sialyl $\mathrm{Tn}(\mathrm{STn})$, is responsible for increased expression of $\alpha$ - $N$-acetylgalactosamine ( $\alpha$-GalNAc). The $\alpha$-2,6-sialyltransferase I 
(ST6GalNAc-I) or mutations of C1GalT1-specific chaperone 1 (C1GALT1C1) have also been reported as involved in invasion and migration of malignant cells [20], as have alterations of $N$ - and $O$-glycans on integrins [42]. Changes in protein glycosylation also affect protein interactions. Alterations of vascular endothelial growth factor receptor (VEGFR) glycosylation change the ability of Galectins to recognise VEGFR, effectively promoting angiogenesis [43]. The tumour-associated antigens (sTn), sialyl Lewis $\mathrm{x}\left(\mathrm{SLe}^{\mathrm{x}}\right)$ and $\mathrm{SLe}^{\mathrm{a}}$ are well known ligands for cell adhesion. These are found in activated endothelial cells (E-selectin), platelets (P-selectin) and leukocytes (L-selectin), thus promoting malignant cell adhesion and metastasis [44, 45].

Aberrant glycosylation is associated with epithelial-to-mesenchymal transition (EMT) and metastasis. Cancer metastasis refers to the spreading of tumour cells from the primary cancer site to other organs via the lymphatic and/or vascular networks. Metastases account for the majority of cancer-related deaths. A series of events is involved, broadly categorized into cell invasion, intravasation and extravasation. During invasion, malignant cells lose adhesion, become more motile and separate from the primary tumour. EMT is the process whereby epithelial cells lose their polarity and cell-cell adhesion, due to repression of E-cadherin, and gain migratory properties: malignant cells break through the basement membrane and travel into lymphatic and vascular vessels, where they become CTCs. These can then extravasate via trans-endothelial migration and enter the parenchyma of the distant organ, establishing a metastasis $[46,47]$.

Aberrant glycosylation influences cancer metastasis [48]. Malignant epithelial tumours regularly show striking characteristics of altered glycosylation. Overexpression of particular $\mathrm{N}$-glycan structural features such as GnT-V catalysed branching ( $\beta 1-6 \mathrm{GlcNAc}$ ) interferes with epithelial cadherin associated cell-cell adhesion and promotes tumour cell disassociation and invasion, triggering epithelial-mesenchymal transition (EMT) [49]. Various glycoconjugates such as tumour associated $\mathrm{T} / \mathrm{Tn}$-antigen and glycan binding proteins such as galectins, selectins have been identified to participate in the EMT process. Additionally, mucins, integrins and laminins all carry glycans with terminal epitopes such as sLex, sLea, which play a role in extravasation of cells that can cause metastases in distinct organs $[30,50,51]$. The most frequently reported glycans, glycosyltransferases and glycoproteins associated with igniting metastatic processes are summarised in Table 1. 
Table 1: Most commonly described glycans, glycosyltransferases and glycoproteins associated with cancer metastasis

\begin{tabular}{|c|c|}
\hline Type of glycosylation & Molecular Targets \\
\hline $\mathrm{N}$-glycosylation & $\begin{array}{l}\text { - High MGAT5 (GnT-V) expression that trigger the biosynthesis of } \beta 1,6 \\
\text { GlcNAc-branched } N \text {-glycans [41] } \\
\text { - sialylated } N \text {-glycans [52] } \\
\text { - Poly } N \text {-acetyllactosamine (polylacNAc) bind with galectin-3 [53] } \\
\text { - Overexpression of the enzyme DPAGT1, which is activated by the Wnt/ } \beta \text { - } \\
\text { catenin [54] } \\
\text { - Integrin } \alpha 6 \beta 4, \beta 1 \text {-integrin branching [55] } \\
\text { - integrin ligand laminin-332 [56] } \\
\text { - Enzymes such as RPN1 (ribophorin) [57], RPN2, N33 (TUSC3) [58], GCS1 } \\
\text { and GANAB [59], ST6GAL1 [60], FUT8 [61] }\end{array}$ \\
\hline$O$-glycosylation & $\begin{array}{l}\text { - The tumour-associated Tn, sTn antigen [62], and its interaction with } \\
\text { galectin-3 [63] } \\
\text { - Mucin } 1 \text { (MUC1) modulated via C1GALT1 potentiate MUC1-C/B-catenin } \\
\text { signalling [64] } \\
\text { - Cell-surface glycoprotein CD44 [65] } \\
\text { - alteration of integrin } \beta 1 \text { via C1GALT1 [66] } \\
\text { - Siglecs, galectins and selectins [67] } \\
\text { - Overexpression of GALNTs [68] } \\
\text { - High Sialyl transferase ST3GAL6 [69] }\end{array}$ \\
\hline
\end{tabular}

\subsection{Liquid biopsy}

A liquid biopsy is a simple, minimally invasive method of profiling the tumour status of a cancer patient. Liquid biopsy enables analysis of cell-free nucleic acids, mainly free DNA (cfDNA) and tumour DNA (ctDNA). Identification of CTCs and circulating glycoconjugates can thus assist in monitoring cancer metastasis and recurrence of a primary neoplasm, including treatment response and evaluation of newer treatments [70]. Liquid biopsy assays can search for, and characterize minimal residual disease (MRD), viz: the spreading of tumour cells to distant organs from the primary origin without having grown to sufficient size to produce physical - including radiological - signs of metastasis [71]. Liquid biopsies can be taken frequently, enabling determination of the evolution of new genetic profiles of the neoplastic cell populations, their protein identities and their glycosylation changes associated with metastases [72-75]. 


\subsection{Circulating Tumour Cells (CTC)}

CTCs are the seeds of cancer metastases obtained from the blood of cancer patients. Their detailed molecular characterisation not only improves fundamental understanding of cancer progression and metastasis, but also offers opportunities for predicting treatment response and recurrence. In addition, clusters of CTCs (groups of two or more aggregated CTCs) [74] may reflect the structure and behaviour of the primary neoplasm, and of any established metastases, which may assist in both diagnosis and treatment planning, especially where the primary tumour remains occult. CTCs and clusters are also exploited to develop patient derived xenograft (PDx) models, which are used for preclinical testing of new drugs, and for screening the sensitivity of tumours to existing drugs (Table 2) [76].

Table 2: Utilisation of CTCs as a cancer biomarker

\begin{tabular}{|ll|l|}
\hline Enumeration and profiling of CTCs & Biological characterisation of CTCs \\
\hline 1) Screening CTCs for diagnostic purposes [77, 78] & 1) Snapshots of the molecular makeup [82] \\
2) Cellular nuclear size analysis and guide for & 2) Protein glycosylation and metastasis [75, 83] \\
& disease prognosis [79] & 3) DNA methylation [84] \\
3) Treatment response, clinical progress and & 4) Gene mutation [85, 86] \\
& recurrence [80] & 5) CTCs derived PDx models for drug \\
4) Tumour heterogeneity monitoring [81] & discovery [76]
\end{tabular}

Currently, techniques including di-electrophoresis, combined with the use of antibodies targeting epithelial cell adhesion molecules (EpCAM), or tumour associated antigens such as cytokeratin (CK)18, CK19, mucin-1 (MUC-1), and mammaglobin have been used to isolate and detect CTCs, sometimes within "point of care" microfluidic devices (Figure 4) [87]. Glycan-based detection of CTCs holds promise: however, only few studies have been published to date on this topic (Table 4). 


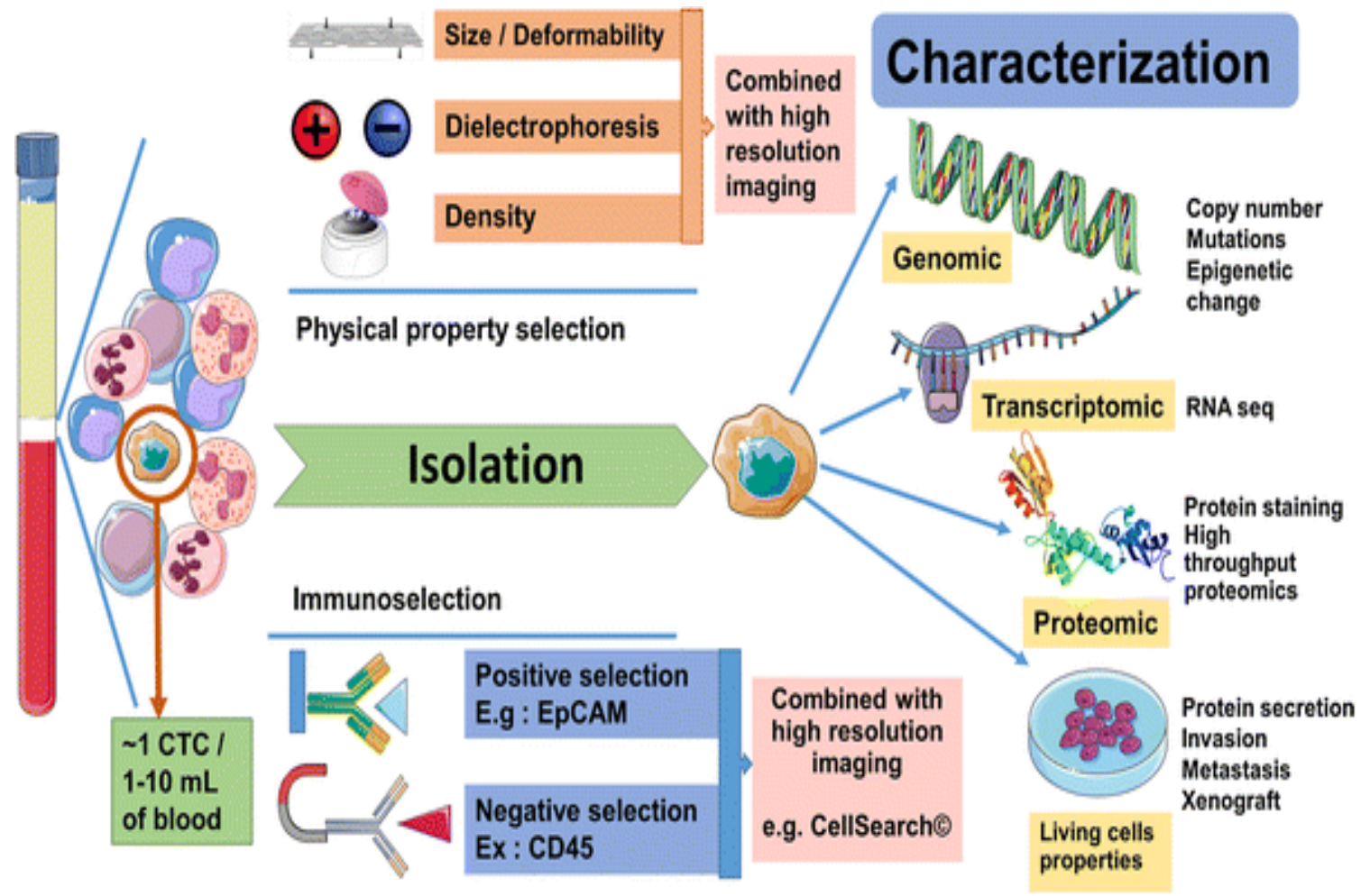

Figure 4: Isolation and characterization of CTCs. Peripheral blood is collected from cancer patients, CTCs are isolated through positive (EpCAM) or negative (CD45) immune selection processes or systems based on physical properties, including cell size, di-electrophoresis or density through a microfluidic device. Cells are then visualized with high resolution imaging and can undergo genomic profiling, transcriptomic or proteomic analysis and both in-vitro (cell culture), and in-vivo studies in animals. Figure reproduced with permission from reference [88].

\section{Glycosylation changes as biomarkers and therapeutic targets for HNSCC}

The changes occurring in epithelial cells during carcinogenesis, tumour progression and metastasis involve widespread changes in their glycosylation. These are a hallmark of cancer [36], but their diagnostic potential is not yet fully exploited. Several techniques have been used to characterise glycosylation changes in the primary tumour tissues of HNSCC patients, their body fluids as well as in cancer cell line models (Table 3). Relevant studies published within the past ten years are summarised in this review. We categorise studies into three groups based on the sample source: tumour tissue and cultured cells; blood or serum; and saliva.

\subsection{Glycosylation in HNSCC tumour tissues and cultured cells:}




\subsubsection{Overexpression of GnT-V enhances CEACAM6 $N$-glycosylation, promoting EGFR signalling and poor prognosis}

The glycosyltransferase GnT-V is encoded by the MGAT5 gene. It catalyses the addition of a $\beta 1-6$ linked GlcNAc on the $\alpha 1-6$-linked mannose of $N$-glycans, which usually is the basis for further elongation of the $N$-glycan structure [89]. Alterations of GnT-V expression occurring on EGFRs is suggested to promote metastasis [90]. Increased GnT-V expression has been reported in radioresistance nasopharyngeal carcinoma cells [91].

GnT-V also modulates $N$-glycosylation on CEACAM6, another potential tumour marker. CEACAM6 is a member of the carcinoembryonic antigen protein family. It is a heavily glycosylated molecule upregulated in multiple cancer types and linked to cancer progression [92]. Chiang et al. [93] demonstrated that elevated expression of glycosylated CEACAM6 could be predictive of recurrence of OSCC. They engineered anti-CEACAM6 Abs (TMU) with a single-domain (sd)Ab or a heavy-chain (HC)Ab that specifically recognizes glycosylated CEACAM6. Using multiple cancer cell lines and severely compromised immune deficiency (SCID) mice, they showed that CEACAM6 expressing cells were highly invasive while CEACAM6 silencing by shRNA induced a sluggish growth rate.

CEACAM6 was also shown to modulate invasion and migration of OSCC cells when simultaneously GnT-V expression is increased. Chiang et al. also reported that CEACAM6 upregulation was associated with enhanced migration of an OSCC cell line through the phosphorylation and downstream signalling of the EGFR pathway. Swainsonine, an inhibitor of mannosidase II, inhibits the biosynthesis of complex type $\mathrm{N}$-glycans, thus blocking further opportunities for attaching sialylated and/or fucosylated glycoepitopes to $\mathrm{N}$-glycans (Figure 2). Treatment with swainsonine suppressed the CEACAM6promoted, EGF-induced cell migration and proliferation while control cells were unaffected. Inhibiting GnT-V expression not only inhibited CEACAM6-enhanced cell migration, but also supressed EGFR signalling. An anti-CEACAM6 Ab (TMU) significantly inhibited cellular invasion and migration, suggesting that targeting glycosylated CEACAM6 with the TMU antibody could be a viable therapeutic approach for OSCC.

\subsubsection{GALNTs enhances EGFR signalling and may be an attractive therapeutic target}

Alterations of glycosylation in cancers are frequently attributed to altered expression of GalNAc-Ts $[94,95]$ and associated with enhanced cell proliferation, migration and invasion [96]. C1GALT1, the glycosyltransferase responsible to form core 1 type $O$-glycans, has also been found overexpressed in multiple types of cancer, promoting metastasis through EGFRs upregulation, supporting its role as a potential therapeutic target $[64,97]$.

The study from Dong et al. [98] demonstrated that C1GALT1 overexpression increases core 1 type $O$ glycan, which promotes radio-resistance in human laryngeal carcinoma cell lines such as the 
radioresistant Hep-2max and the radiosensitive Hep-2min. In lectin microarray analyses: the Hep-2 max cell line showed higher levels of core 1 type $O$-glycans. Blocking of $O$-glycan synthesis by benzyl- $\alpha-$ GalNAc restored the radio-sensitivity. The levels of $O$-glycans such as Sia2-6Gal $\beta 1-4 \mathrm{GlcNAc}$ and core 1type $O$-glycans (Gal $\beta 1-3 \mathrm{GalNAc} \alpha-\mathrm{Ser} / \mathrm{Thr}$ ) were increased both in cancer cells and laryngeal carcinoma tumour tissue. Furthermore, knockdown of C1GALT1 in Hep-2max cells also suppressed proliferation of malignant cells. Using the peanut agglutinin (PNA) lectin that recognises core 1 type $O$-glycans, higher levels of this PNA-reactive $O$-glycan were found on Integrin $\beta 1$ from Hep-2max cells compared to integrin $\beta 1$ from Hep-2 min cells. Selective blocking of integrin $\beta 1$ also made cells more responsive to treatment. Lectin histochemistry performed on primary tumour tissues confirmed higher expression levels of aberrant core 1 type $O$-glycans (PNA-recognized $O$-glycans), which closely correlated with patient survival. Tumour patients with low core 1 expressed $O$-glycans displayed a significantly longer survival than patients with high levels of $O$-glycan expression $(\mathrm{P}<0.05)$.

Lin et al. [97] also showed that modified $O$-glycan expression by C1GALT1 contributed to EGFR upregulation and an aggressive tumour cell phenotype. This study reported that the C1GALT1 protein is significantly upregulated in HNSCC compared to normal oral mucosa and proposed the use of C1GALT1 overexpression as a potential marker of poor overall survival. Disease free survival and overall survival rates were significantly better in patients with low C1GALT1 expression, which was monitored over a three-year period. In addition, blocking of C1GALT1 was also shown to suppress the malignant phenotype both in-vitro and in-vivo through EGFR signalling inhibition. Knockdown of C1GALT1 using siRNA in multiple HNSCC cell lines significantly reduced cell viability, migration, invasion. In addition, in a mouse tumour xenograft model $(n=7)$, the growth of C1GALT1 knockout cells was significantly lower compared to wild type cells. Furthermore, a phospho-RTK array also demonstrated that C1GALT1 knockout primarily reduced the phosphorylation of EGFR. Itraconazole, a pharmacological C1GALT1 inhibitor, reduced tumour growth in mouse xenografts model $(\mathrm{n}=8)$. Therefore, both in-vitro and in-vivo data suggests that C1GALT1 may be regarded as an attractive therapeutic target for HNSCC. Nevertheless, given the central involvement of C1GALT1 in $O$ glycosylation (Figure 3) also in normal cells, a C1GALT1 targeted treatment might not be specific enough and lead to severe side reactions.

In an earlier work, Lin et al. [99] showed that overexpression of GALNT2 enhances invasive properties of OSCC and increases EGFR activity, thus promoting carcinogenesis. GALNT2 was significantly overexpressed in 73\% (35/48) of primary OSCC tissues in compared to non-malignant tissues, which was associated with phosphorylation of EGFR and AKT. Furthermore, GALNT2 overexpression also enhanced EGF-induced OSCC cell migration and invasion. These findings suggested that targeting GALNT2 could be a potential approach for the treatment of OSCC, though we are not aware of any further attempts that targeted GALNT2 in a clinical setting. GALNT1 expression levels, however, 
were markedly high in all cells and tissues tested, indicating that further studies using in-vivo data are required to verify the specific role of GALNT2 in OSCC pathogenesis.

Another study from Harada et al. [100] showed that mucin type $O$-glycosylation is produced due to an increased expression of GALNT3. This has been linked to the pathogenesis of early stage OSCC and was indicative for poor disease-free survival. Overexpression of GALNT3 occurred in OSCC tumour tissues from stage I and II $(n=110)$, but not in adjacent normal tissues. Although GALNT3 overexpression of was higher in patients with recurrent OSCC, sensitivity was relatively low [strongly expressed in 19 (54.3\%) and weakly in 16 (45.7\%)]. The authors also reported that lower GALNT3 expression in early stage OSCC correlated with a better progression free survival compared to patients with OSCC high GALNT3 expression levels $(\mathrm{p}=0.034)$. Kaplan-Meier analyses indicated that patients with strong GALNT3 expression had a significantly shorter, postoperative, median disease-free survival (11.8 months) compared to those with a weak expression (32.7 months), especially within the first two rather than five years postoperatively $(P<0.001$ (2 years) and $P<0.01$ (5 years). Suppression of GALNT3 in HSC-2 (human OSCC cell line) in vitro induced decreased cell proliferation, migration and invasion, together with cell cycle arrest. Additionally, other GALNTs such as GALNT1, GALNT2, GALNT3, GALNT4, and GALNT6 were also tested by immunocytochemistry in the HSC-2 cell line: GALNT3 was expressed at higher levels than other GALNTs, suggesting that GALNT3 could be an OSCC-specific prognostic biomarker for the clinical management of OSCC, particularly for early cases. However, this study needs to be further validated in properly designed prospective clinical trials.

Wiest et al. [101] showed that altered mucin-type $O$-glycosylation is a driver for tumour-associated TA-MUC1 overexpression in laryngeal malignant keratinocytes and normal tissues of the head and neck. The humanized monoclonal antibody PankoMab-GEX targeting TA-MUC1 showed strong staining in malignant tissue but not in non-tumour tissues. Although this study did not clearly disclose which specific type of TA-MUC1 is recognised by the PankoMab-GEX antibody, it supports the notion that the PankoMab-GEX ${ }^{\mathrm{TM}}$ holds potential for the identification and further characterisation of high-grade tumours and could be used for disease monitoring.

\subsubsection{Sialylation modulates EMT and EGFR signalling in HNSCC}

The level of sialylation on the cell surface can be influenced by specific sialyltransferases, and by the presence of sialidases, such as NEU3, which may remove terminal sialic acids. Aberrant expression of plasma membrane-associated sialidase NEU3 is closely involved in the pathogenesis of multiple cancers [102, 103]. Shiga et al. [104] found that overexpression of the plasma membrane-associated sialidase NEU3 enhances EGFR phosphorylation in HSC-2 cells. NEU3 mRNA levels were increased in $73 \%$ of HNSCC tumour tissue specimens compared to surrounding non-tumour tissue [104]. While NEU3 upregulation enhanced cell migration and invasion, blocking NEU3 with siRNA inhibited these effects. The authors also reported that NEU3 silencing reduced $N$-cadherin, MMP-9 and EGFR 
expression. Blocking EGFR phosphorylation was shown to suppress MMP-9 activity. Further studies are required to confirm the sensitivity and specificity of NEU3 as a diagnostic or prognostic biomarker. Similarly, based on available evidence, it remains to be seen whether NEU3 could be a promising drug target for HNSCC treatment.

\subsubsection{Lectin based tissue staining is assertive for identification of glycans as biomarkers}

Lectins are proteins or glycoproteins that can be used for detection of glycans. Baeten et al.[105] used a fluorophore-conjugated lectin-based optical imaging approach to detect sialic acids in tumour tissue sections. Oral malignant tissues were analysed by optical imaging through topically administrated fluorescently labelled lectin such as Alexa Fluor 647 conjugated wheat germ agglutinin (WGA). WGA, however, is not just recognising sialic acid residues but also terminal GlcNAc. Using this fairly broad specific WGA probe, a statistically significant (signal noise ratio of $5.88 \pm 3.46, \mathrm{P}=.00046$ ) increase in fluorescence was detected in malignant compared to normal tissue, while the UV autofluorescence did not show any significantly different absorption (SNR of $1.35 \pm 0.41, \mathrm{P}=.098$ ). Blocking WGA binding using free GlcNAc decreased the fluorescence intensity threefold in malignant tissue.

Borzym-Kluczyk et al. [106] utilized the enzyme-linked immunosorbent assay with a panel of biotinylated lectins. Lectin signals considered representative for sialic acid, Fuc $\alpha 1-6, \alpha 1-2, \mathrm{~T}$, Tn antigens and a1-6 mannose and were significantly higher in salivary gland tumour tissues when compared to normal salivary gland tissues, but again no further work on this topic has been reported.

\subsubsection{Glycoprotein levels (fucosylated B7-H3) determine the size of tumour and treatment responses}

Overexpression of B7 homolog 3 (B7-H3) has been reported in multiple types of cancer [107]. It is a member of the B7 family of immunoregulatory proteins and also known as CD276 isoform 1. B7-H3 is a type-I transmembrane glycoprotein with four Ig-like domains that contain a nearly exact tandem duplication of the $\mathrm{IgV}-\mathrm{IgC}$ domain (4Ig-B7-H3). B7-H3 overexpression has been associated with aberrant glycan expression and cancer pathogenesis. Chen et al. [108] showed that B7-H3 is overexpressed in OSCC cell lines and in tumour tissue in compared to normal tisue, and its expression was associated with a significantly reduced overall survival rate in patients. B7-H3 expression also correlated with a larger tumour size, while B7-H3 knockdown by shRNA resulted in dramatically reduced tumour growth in a mouse model. However, the correlation between B7-H3 expression and tumour size in patient samples was not investigated. B7-H3 derived from cultured CA9-22 cells exhibited a diverse pattern of $\mathrm{N}$-glycosylation, including complex type, hybrid type and fucosylated $\mathrm{N}$ glycans that also carried terminal $\alpha$-galactoses, while Smulow-Glickman cell derived B7-H3 carried mostly biantennary $\mathrm{N}$-glycans that exhibited higher levels of sialylation. B7-H3 from CA9-22 cells also showed a higher interaction with C-type lectins such as DC-SIGN and Langerin, indicating that B7-H3 
glycosylation might play a role in progression of OSCC that needs to be further evaluated in patient malignant tissue.

\subsubsection{Fucosylation and glyco-epitopes in EGFR signalling: potential biomarkers for HNSCC}

Fucosylation has also been associated with HNSCC progression. Desiderio et al. [109] showed that fucosyltransferases such as FUT3 and FUT6 upregulation enhances sialyl Lewis X (SLe ${ }^{\mathrm{x}}$ ) expression, which also promote adhesion and metastasis. Along that line, blocking of fucosylation suppresses orosphere formation and cancer stem cells invasion. Orospheres in OSCC showed resistance to cisplatin and radiation treatment in vitro. Orospheres grafted into a mouse model showed increased tumour size, however the relationship between tumour size and FUTs expression was not evaluated. Similarly, this study failed to prove any correlations between FUTs and tumour metastasis. It is also demonstrated that overexpression of FUT8 resulted in upregulation of the cell surface EGFR and corresponding downstream signaling in multiple cancers $[110,111]$, however in HNSCC, activities of FUT8 never been tested. Further investigations are required to identify the sensitivity and specificity of FUTs as biomarkers for OSCC management. The relevance of fucosylation in OSCC is also indicated by the work from Lin et al. [112], which showed that FUT1, FUT2, FUT3 and $\mathrm{Le}^{\mathrm{y}}$ antigens were overexpressed in OSCC cells. Furthermore, they demonstrated that $\mathrm{Le}^{\mathrm{y}}$ is present on EGFR and may contribute to the activation of the EGFR signalling pathway. Notably, blocking of $\mathrm{Le}^{\mathrm{y}}$ glycosylation in OSCC cell lines abrogated the EGFR-mediated AKT and ERK signalling, and as such cellular migration thus, providing the rationale for further studies aimed at assessing the role of $\mathrm{Le}^{\mathrm{y}}$ glycosylation as a potential therapeutic target.

\subsubsection{DPAGT1 overexpression confers enhanced migratory properties to HNSCC cells in- vitro}

DPAGT1 is the key driver for $N$-glycosylation as it catalyses the first step of the $N$-glycan precursor biosynthesis [113]. As such, changes in the activity of this enzyme have lasting effects on all glycoproteins synthesised by a cell. Loss of function mutations in the DPAGT1 gene will have a negative impact on cell survival, and thus are less likely to be occurring in cancer cells [114]. DPAGT1 overexpression has been reported in tumour tissues of some cases of oral cancer [115]. Studies have investigated the effect of DPAGT1 overexpression on selected glycoproteins such as E-cadherin or the protein collagen triple helix repeat containing 1 (CTHRC1), which are both involved in critical cell-cell interactions. Hyper- and hypo-glycosylation of DPAGT1 increases cell migration, reduces intracellular adhesion of proteins such as E-cadherin and upregulates CTHRC1 [40, 115]. Jamal et al. [116] also reported that DPAGT1 overexpression was present in primary OSCC malignant tissue compared to non-malignant tissue. Overexpression of DPAGT1 correlated with increased canonical Wnt signalling activation and binding with both $\beta$ - and $\gamma$-catenins in OSCC cells, while partial blocking of DPAGT1 using siRNA inhibited the canonical Wnt activity. While these observations are a clear indication of the 
importance of glycosylation in HNSCC pathogenesis, these studies, however, fail to acknowledge that changes in DPAGT1 expression and its activity have widespread effects across glycoproteins expressed in these cells. Thus, the observed effects might not just be due to changes in the glycosylation of selected glycoproteins, but the outcomes of a more global effect.

\subsection{Glycosylation in HNSCC patient sera:}

\subsubsection{Tri-antennary and tetra-antennary $N$-glycans with varying degree of sialylation and fucosylation as putative diagnostic biomarkers}

Plasma and serum offer great opportunities for non-invasive diagnostics if molecular signatures can be unambiguously associated with a disease. In consequence, glycosylation of serum/plasma glycoproteins has also been investigated in the context of HNSCC. Guu et al. [117] showed that fucosylated and sialylated tri- and tetra-antennary $\mathrm{N}$-glycans were overexpressed in the sera of patients with OSCC in comparison to the sera from healthy controls. In sera from patients with lymphatic metastases, increased levels of fucosylated di-sialylated, biantennary and fucosylated tetra-sialylated, tetra-antennary $\mathrm{N}$ glycans were found and postulated as potential diagnostic biomarkers. Nevertheless, changes in serum glycosylation are commonly observed in patients, and can also occur as a consequence of radiation therapy [118], limiting the specificity of such serum-based, glycan-focussed approaches [18]. Guu et $a l,[117]$ however, also screened for anti-glycan antibodies using a glycan-23 Chip and found that, in patients with OSCC, IgM-antibodies directed against the glycolipids SSEA-3 and GD2 were found at increased levels, which could represent a potential diagnostic marker for HNSCC, though its overall sensitivity and specificity need to be verified.

\subsection{Glycosylation in the saliva of HNSCC patients:}

\subsubsection{Sialic acid as potential biomarker from saliva}

Because of the anatomical proximity of many HNSCCs, saliva, or what we prefer to call "whole mouth fluid"** is an attractive source of potential biomarkers. A number of studies have analysed "saliva" collected from healthy volunteers, potentially malignant oral conditions and oral cancer patients with respect to various glyco-features. Total sialic acid (TSA), sialidase activity, sialic acid linkage ( $\alpha 2-3$ and $\alpha 2-6)$ on sialoproteins and sialyltransferase activity in saliva have been evaluated. The TSA/total protein ratio as well as the activities of $\alpha 2-3$ and $\alpha 2-6$ sialyltransferases were significantly higher in patients with metastatic malignant keratinocytes compared to patients with potentially malignant oral conditions [119-122]. Sinevici et al. [123] recently used saliva $N$-glycan profiling of fluorescently labelled $\mathrm{N}$-glycans to demonstrate that healthy individuals exhibited a more homogenous glycosylation pattern compared to oral cancer patients. Future work on larger and well-defined patient cohorts will be necessary to validate the potential diagnostic opportunities embedded in saliva glycoprotein glycosylation. 
** "Fluid collected from the mouth is a mixture of the secretions of major and minor salivary glands, of transudate from the mucous membranes of the whole upper aerodigestive tract, of inflammatory exudate from gingival crevicular fluid and areas of erythema and ulceration of mucous membranes: the latter inevitable if a malignant neoplasm is present. It thus contains soluble products from serum, immune inflammatory cells, desquamated normal epithelial cells, and cells shed from any neoplasm present" [124]. 
1 Table 3: Current knowledge on protein glycosylation and associated changes in HNSCC.

\begin{tabular}{|c|c|c|c|c|c|}
\hline Study & Sample source & $\begin{array}{l}\text { Healthy } \\
\text { cohort }\end{array}$ & $\begin{array}{l}\text { Patient } \\
\text { cohort }\end{array}$ & Methodology used & Major findings \\
\hline
\end{tabular}

$\underline{\text { Tissue }}$

[93]

10 and 38 FFPE,

primary cells OC-2 and

OEC-M1 lines

[98]

HepG2 cell line,
laryngeal carcinoma
tissue

tissue

[97]

HNSCC tissue and $\mathrm{N}=8$

SAS, Fadu cell lines

[101]

Laryngeal carcinoma $\mathrm{N}=7$ tongue, $\mathrm{N}=128$

tissue, followed by vocal cord,

FFPE

larynx,

pharynx and

epiglottis

$\mathrm{N}=49$
Surgical HNCSC tissue

samples, Cell lines:

HSC-2 andSAS
$\mathrm{N}=48, \quad$ anti-CEACAM6 $\mathrm{Ab}$ (TMU) heavy Overexpression of MGAT5 (=GnT-V protein) early-stage chain antibody to recognize enhances CEACAM6 $\mathrm{N}$-glycosylation, promoting

OSCC glycosylated CEACAM6 $\quad$ EGFR signalling and poor prognosis

patients

lectin microarrays containing $91 \mathrm{C} 1 \mathrm{GALT} 1$ overexpression regulates $O$-glycans on lectins, expression of core 1-type O- integrin $\beta 1$ and thereby promoting radioresistance glycans by flow cytometry and lectin blot analysis

$\mathrm{N}=153$ In-gel digestion of protein, LC- C1GALT1 modifies $O$-glycans on EGFR, showing MS/MS analysis and lectin pull- aggressive tumour phenotype and act as a down assay therapeutic target

peroxidase-labelled humanized TA-MUC1 overexpressed and a good target for monoclonal antibody PankoMab- antibody therapy with PankoMab-GEX ${ }^{\mathrm{TM}}$ GEXTM)

$\mathrm{N}=30$ quantitative RT-PCR analysis for plasma membrane-associated sialidase (NEU3) mRNA expression of NEU3, upregulation modify EGFR for tumour progression western blot, immunocytochemistry and alteration of EMT and Sialidase activity assay 
[108]

Ca9-22 cell line, normal

tumour tissue from cells

patients

[100]

Surgically resected

ESOSCC, FFPE tissue

Freshly extracted oral cancer tissue samples (scalpel and punch biopsies)

OSCC cell lines such as Ca92-2, SAS, OEC$\mathrm{M} 1$, and OC3 and FFPE

Surgical collection of $\mathrm{N}=14$ salivary gland tumour tissue
Surgical tissue samples, CAL27 and A253 HNC cell lines

OSCC CAL27 cells and fresh tissue from oral cancer in-solution tryptic digestion, LC- glycoprotein B7-H3 overexpression correlates MS/MS analysis

with tumour size and clinical stage, thus providing a direction for the diagnosis and treatment of OSCC

western blot, immunohistochemistry increased GalNAc-T3 responsible for the and immunofluorescence of pathogenesis of ESOSCC recurrence, shorter DFS, GalNAc-T3 and other GalNAc-Ts a parameter for clinical management of ESOSCC

$\mathrm{N}=7 \quad$ Fluorescence imaging using WGA Lectin based tissue imaging identify cell surface Lectin fluorophore conjugates sialic acid that can provide a new avenue in oral cancer detection

immunohistochemistry for

GALNT2 OSCC tissue microarray.

The Vicia villosa agglutinin (VVA)

pull down assay to detect changes in $O$-glycans

sugar structures on proteins cancer tissue expresses significantly higher sialic, determined by enzyme-linked fucose and T, Tn antigen

immunosorbent assay (ELISA)

with biotinylated lectins

$\mathrm{N}=$ OSCC

5 immunohistochemistry

and aberrant glycosylation dysregulates the immunofluorescence imaging and western blot of DPAGT1

DPAGT1/Wnt/E-cadherin network, which triggers the pathogenesis of oral cancer

quantitative Real-time PCR for altered $N$ - glycosylation correlates with Wnt DPAGT1, Peptide N-Glycosidase signalling and CTHRC1 expression that drives $\mathrm{F}$ digestion, Immunoblotting, OSCC growth and progression 
Salivary epidermoid carcinoma A253 cells, FFPE samples of primary OSCC

$4 \quad$ Blood

[117]

patient sera

$\mathrm{N}=27$

OSCC patients

$(\mathrm{N}=48$ MS analysis

\section{$5 \quad$ Saliva}

[119]
Saliva

Saliva
$\mathrm{N}=100$

$\mathrm{N}=50$ OPC,

$\mathrm{N}=100 \mathrm{OC}$

$\mathrm{N}=46$ treatment

$\mathrm{N}=5 \quad \mathrm{~N}=18$

sialidase, $\alpha$-L-fucosidase activity were performed

spectrofluorometric (4-methy umbelliferone) method; $\alpha 2-6$ and post $\alpha 2-3$ linkage by the biotinylation of lectin; membrane dot blot; and sialyltransferase activity by ELISA

UPLC-mass spectrometry analysis
PNGase F release of $N$-glycan, permethylation and MALDI-TOF

cosylated di-sialylated bi-antennary glycan and fucosylated tetra-sialylated tetra-antennary glycan overexpressed in the serum specimen of OSCC and acts as diagnostic biomarker increased sialidase activity and salivary sialylation oral cancer

\author{
quantitative real-time PCR, DPAGT1 correlates with aberrant N-glycosylation \\ Peptide N-glycosidase $\mathrm{F}$ and and driver for EMT \\ endoglycosidase $\mathrm{H}$ digestions, \\ western blot \\ Immunoprecipitation
}

oli

neutral oligosaccharides consisting of oligomannose, hybrid and complex structures, followed by smaller fractions of mono and disialylated structures that are present in cancerous samples could carry diagnostic potential 


\section{$8 \quad$ Cell line based}

[109]

OSCC cell lines (UMSCC14B,

UMSCC103) and in vivo model

$\mathrm{C}-2$, OEC-M1, and HSC-3 OSCC cell lines cell orospheres formation, fucosyltransferases FUT3 and FUT6 upregulation quantitative mRNA expression and enhances $\mathrm{SLe}^{\mathrm{x}}$ expression, thus promoting flow cytometry of FUTs adhesion and metastasis.

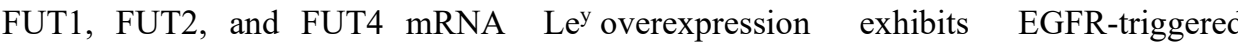
expression by RT-PCR, signalling pathways and may become a tumour immunoblotting biomarker or treatment target 


\section{Glycosylation as a target for liquid biopsy}

Liquid biopsy is emerging as a useful adjunct to tissue sampling in the diagnosis and management of cancer patients. Circulating biomarkers can provide an overview of tumour burden from both primary and metastatic lesions. Liquid biopsies can be used for exploring the molecular underpinnings of tumour progression. CTCs released from the tumour site may provide an enriched source of genetic and molecular information regarding tumour phenotype and aggressiveness. CTC isolation and tracking are important for knowing the correct status of the disease and can be recognised as an important biomarker to early detect metastasis as well as to predict response to treatment. [75, 125].

CellSearch ${ }^{\circledR}$ (Menarini Silicon biosystems) is an FDA approved instrument used for isolation and characterisation of CTCs. In addition, label free technologies such as microfluidics, negative depletion, immunostaining, RT-PCR, and flow cytometry methods exist to isolate CTCs [126-128]. In recent years, mapping of glycan alterations by MS or lectin microarrays has shown potential to improve the specificity and sensitivity of tumour biomarkers. For example, overexpression of GnT-V activity was linked to increased $\mathrm{sLe}^{\mathrm{X}}$ levels that were associated with tumour progression by adhesion of CTCs to vascular endothelial cells as a prerequisite for extravasation at the future metastatic site [129]. Therefore, glycoconjugates could be a potential source for CTCs enumeration and surrogate prognostic and diagnostic biomarker for HNSCC. Multiple studies have shown that sTn, CD45 protein, $O$-core glycan determinant $\mathrm{Gp}(\mathrm{Cl})$ and $\mathrm{sLe}^{\mathrm{x}}$ epitopes are useful tools for isolation of CTCs from patient samples. Since, glycosylation is the most common type of modification in the cellular state, therefore, CTCs should carry characteristic behaviour of glycan modification and their consequences. Currently, there are no studies dealing with glycosylation changes on CTCs derived from HNSCC patients' blood samples. Except for Neves et al., study, which includes HNSCC patients in addition to prostate, colorectal, and pancreatic cancers [75]. We therefore listed studies on other cancer types that have investigated CTCs using glycosylation changes (Table 4). We hope that this review will bring appetite to the field of glycosylation, HNSCC and liquid biopsy in the future.

Table 4: Overview of publications describing glycosylation changes in CTCs isolation

\begin{tabular}{|c|c|c|c|}
\hline Studies & $\begin{array}{c}\text { Biological } \\
\text { samples }\end{array}$ & $\begin{array}{c}\text { Altered } \\
\text { glycosylation } \\
\text { pattern }\end{array}$ & Findings \\
\hline
\end{tabular}

Blood collected bladder Sialyl Tn-antigen $(\mathrm{N}=5)$, colorectal $(\mathrm{N}=12)$,

Head and Neck $(\mathrm{N}=2)$ and glycosylation)
Tumour associated sTn glycan antigen is the biomarker for improved CTCs isolation and 


\begin{tabular}{|c|c|c|c|}
\hline & $\begin{array}{l}\text { pancreatic }(\mathrm{N}=1) \text { cancer } \\
\text { patients }\end{array}$ & & $\begin{array}{l}\text { higher sensitive than size based } \\
\text { microfluidic devices. }\end{array}$ \\
\hline [130] & $\begin{array}{l}\text { Human embryonic kidney } \\
\text { HEK-293T cells, HL60 } \\
\text { (human promyelocytic } \\
\text { leukaemia cells), SKBR-3 } \\
\text { (human breast cancer } \\
\text { cells), and Sp2/0-Ag14 (a } \\
\text { mouse myeloma cells) } \\
\text { and mouse model }\end{array}$ & & $\begin{array}{l}\text { Generation of a mAb to recognize } \\
\text { the glycosylated human CD45 } \\
\text { protein and its application to } \\
\text { isolate CTCs. }\end{array}$ \\
\hline [83] & $\begin{array}{l}\text { Blood collected from } \\
\text { bladder cancer patients } \\
(\mathrm{N}=6) \text { and healthy donors } \\
(\mathrm{N}=6)\end{array}$ & Sialyl-Tn & $\begin{array}{l}\text { Sialyl-Tn is expressed in CTCs of } \\
\text { tumour cells and represents a } \\
\text { novel biomarker for targeted } \\
\text { therapy }\end{array}$ \\
\hline [131] & $\begin{array}{l}\text { Blood from metastatic } \\
\text { tumour patients, and lung } \\
\text { (A549)- and breast (T47D } \\
\text { and SKBR3) cell lines }\end{array}$ & $\begin{array}{l}O \text {-core glyco- } \\
\text { determinant } \\
\operatorname{gp}(\mathrm{C} 1)\end{array}$ & $\begin{array}{l}\text { O-core glycan determinant marker } \\
\mathrm{Gp}(\mathrm{C} 1) \text { is a potential } \\
\text { immunological target of breast } \\
\text { cancer CTCs and CTCs screening } \\
\text { could potentially tell metastasis } \\
\text { burden. }\end{array}$ \\
\hline [132] & $\begin{array}{l}\text { Blood collected from } \\
(\mathrm{N}=20) \text { breast cancer } \\
\text { patients and cell line were } \\
\text { used in experimental } \\
\text { design }\end{array}$ & $\begin{array}{l}O \text {-glycosylation } \\
\text { (PCR based } \\
\text { detection) }\end{array}$ & $\begin{array}{l}\text { Upregulation of FUT3, GALNT6 } \\
\text { and ST3GAL3 genes may show } \\
\text { the potential to identify CTCs, } \\
\text { however, this study fails to find } \\
\text { significant correlation between } \\
\text { these glycosyltransferases and } \\
\text { CTC isolation }\end{array}$ \\
\hline [133] & $\begin{array}{l}\text { Blood from advanced } \\
\text { breast cancer patients } \\
(\mathrm{N}=27) \text {, CTC isolated } \\
\text { with CellSearch }{ }^{\mathrm{TM}} \text { and } \\
\text { glycan changes analysed }\end{array}$ & $\begin{array}{l}\text { Sialyl Lewis } \mathrm{x} \\
\text { (sLex) antigen }\end{array}$ & $\begin{array}{l}\text { Sialyl Lewis } \mathrm{x}\left(\mathrm{sLe}^{\mathrm{x}}\right) \text { epitopes are } \\
\text { notably higher in patients with } \\
\text { isolated CTCs } \geq 5 / 7.5 \mathrm{ml} \text { in } \\
\text { comparison with patients with } \\
\text { CTCs }<5 / 7.5 \mathrm{ml}\end{array}$ \\
\hline
\end{tabular}

with HPLC. 


\section{Conclusion and future prospects}

Glycoconjugates are essential molecules for all living cells. Alterations in protein glycosylation are common pathological features observed in many systemic diseases, not only cancer, where they are clearly contributing to progression and metastasis [134]., The ability to capture and understand diseaserelated changes in glycosylation opens novel opportunities for disease diagnosis and intervention. In the context of HNSCC, numerous $\mathrm{N}$-glycosylation-associated markers have been reported at protein level (MGAT5, NEU3, FUT3, and FUT6), glyco-epitope level (Lewis ${ }^{\mathrm{y}}$ and SLe ${ }^{\mathrm{x}}$ ) and glycoprotein level (fucosylated B7-H3, EGFR): many are associated with EMT and metastasis (Table 3). $O$-glycosylationassociated gly-co-syl-trans-ferases such as C1GALT1, GALNT2 and GALNT3, as well as glycoepitopes TA-MUC1 and $O$-GalNAc, which are also present on glycoproteins such as EGFR, have also been suggested to provide novel opportunities for diagnosis, prognosis and, potentially, therapy of HNSCC (Table 3). Additionally, sialyl-Tn antigen, glycosyltransferases such as FUT3, GALNT6 and ST3GAL3, glycan epitope sLe ${ }^{\mathrm{x}}$ and glycoprotein targeted antibodies are potential sources for CTCs isolation and disease monitoring (Table 4). Numerous glycoproteins and glyco-epitopes are already FDA-approved markers in other types of cancer [18]. Currently, glycoprotein biomarkers for screening activity in HNSCC are mainly limited to research settings, hence there are enormous opportunities for specific glycosylation-associated markers in HNSCC diagnosis and therapy still to be identified and validated.

This review provides the first comprehensive summary of current knowledge on glycosylation in HNSCC and recent developments in liquid biopsy technologies for capturing CTCs. These advances pave the way for many new opportunities to translate the next generation of markers from research into the clinic (Figure 5). 


\section{Glycosylation changes in HNSCC}
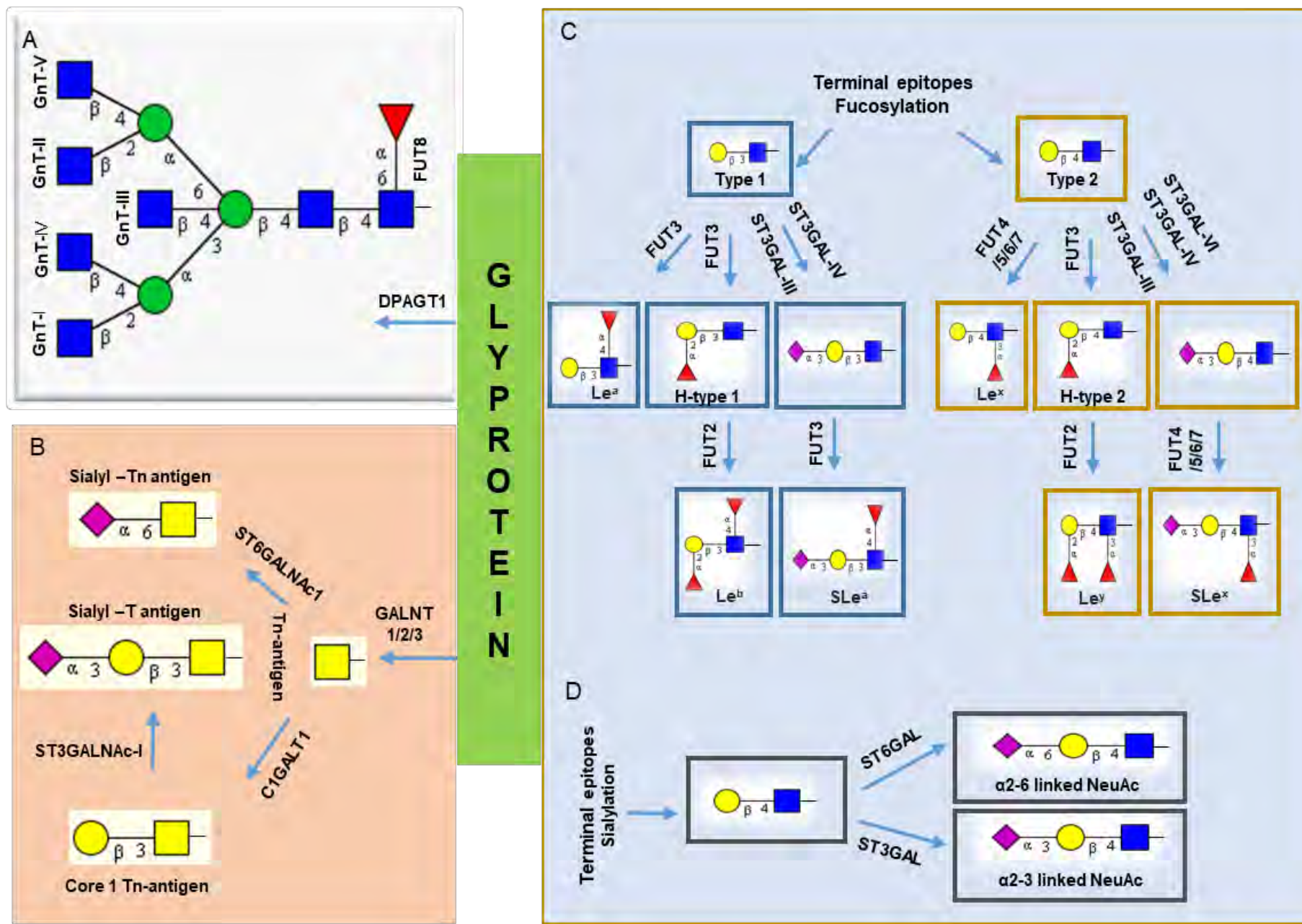

N

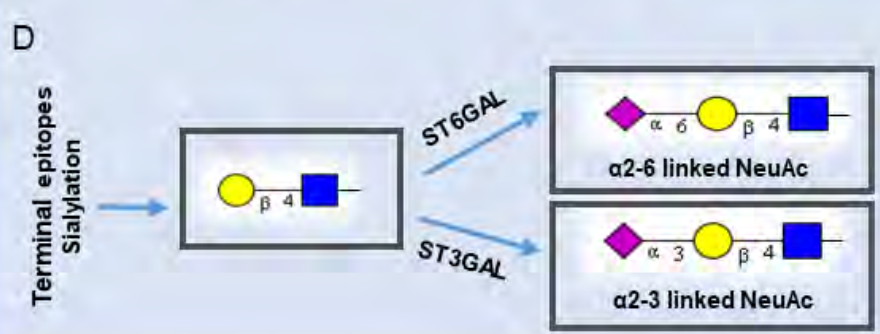

E

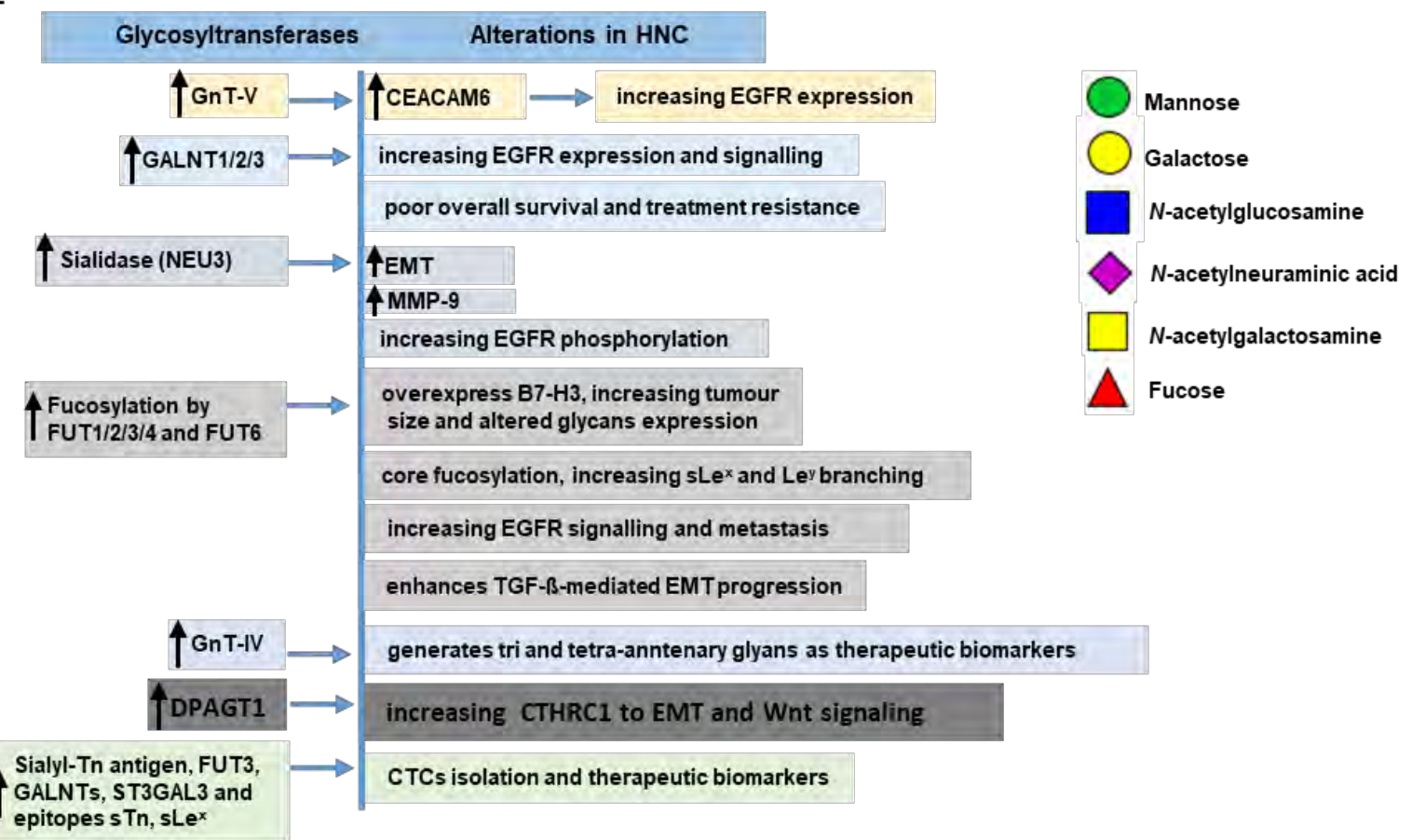


60 Figure 5: Role of glycans and glycoconjugates in HNSCC.

61 A. $N$-glycans are attached to asparagine residues and are modified by different glycosyltransferases into 62 a complex array of possible structures.

63 B. $O$-glycans are attached to the protein via serine/threonine residues and extended by numerous $O$ 64 glycan specific glycosyltransferases.

65 C. Overview of Lewis blood group antigens. $N$-glycans and mucin type $O$-glycans both can be 66 further modified to carry type one and type two chains. These forms are also known as $\mathrm{N}$ 67 acetyllactosamine (LacNAc) repeats. Type one and type two units can be further modified by 68 glycosyltransferases that transfer fucose and or sialic acids (NeuAc), generating fucosylated and or 69 sialylated structures.

70 D. Galactose residues in $N$ - and $O$-glycans can be modified by $\alpha 2-3 / 6$ sialyltransferase (such as 71 ST3GAL and ST6GAL) to cap glycan chains with this negatively charged sugar known to be a 72 relevant sugar for cell-cell interactions.

73 E. A short overview on the current knowledge on HNSCC-related glycoproteins and glycosylation 74 features with diagnostic/therapeutic biomarker potential. 


\section{Acknowledgement}

Chamindie Punyadeera (CP) is receiving research-funding support from the Cancer Australia (APP1145657) and the Garnett Passé and Rodney Williams Foundation. NHMRC ECF to AK (APP1157741). National Breast Cancer Foundation (IIRS-18-047) and Cancer Council Queensland (APP1145758, APP1165064) to RD. This research is also supported by an Australian Government Research Training Program (RTP) Scholarship to Mohammad Rasheduzzaman (MR). DK is the recipient of an Australian Research Council Future Fellowship (project number FT160100344) funded by the Australian Government.

\section{Conflict of interest}

All authors declare no conflicts of interest.

\section{References}

[1] A. Sklan, D. Collingridge, Treating head and neck cancer: for better or for worse?, The Lancet. Oncology 18(5) (2017) 570-571.

[2] F. Bray, J. Ferlay, I. Soerjomataram, R.L. Siegel, L.A. Torre, A. Jemal, Global cancer statistics 2018: GLOBOCAN estimates of incidence and mortality worldwide for 36 cancers in 185 countries, CA: a cancer journal for clinicians 68(6) (2018) 394-424.

[3] S.C. Jayaram, S.J. Muzaffar, I. Ahmed, J. Dhanda, V. Paleri, H. Mehanna, Efficacy, outcomes, and complication rates of different surgical and nonsurgical treatment modalities for recurrent/residual oropharyngeal carcinoma: A systematic review and meta-analysis, Head \& neck 38(12) (2016) 18551861. [4] NCCN Guidelines ${ }^{\circledR}$ \& Clinical Resources. https://www.ncen.org/professionals/physician_gls/default.aspx\#site. [5] R. Shaw, N. Beasley, Aetiology and risk factors for head and neck cancer: United Kingdom National Multidisciplinary Guidelines, The Journal of laryngology and otology 130(S2) (2016) S9s12.

[6] M. Taberna, M. Mena, M.A. Pavon, L. Alemany, M.L. Gillison, R. Mesia, Human papillomavirusrelated oropharyngeal cancer, Annals of oncology : official journal of the European Society for Medical Oncology 28(10) (2017) 2386-2398.

[7] J.H. Maxwell, J.R. Grandis, R.L. Ferris, HPV-Associated Head and Neck Cancer: Unique Features of Epidemiology and Clinical Management, Annu Rev Med 67 (2016) 91-101.

[8] W.C. Spanos, P. Nowicki, D.W. Lee, A. Hoover, B. Hostager, A. Gupta, M.E. Anderson, J.H. Lee, Immune response during therapy with cisplatin or radiation for human papillomavirus-related head and neck cancer, Archives of otolaryngology--head \& neck surgery 135(11) (2009) 1137-46.

[9] N.W.J. Jatin P. Shah, Oral and Oropharyngeal Cancer, Routledge, Taylor and Francis group 2. [10] M. Becker, H. Zaidi, Imaging in head and neck squamous cell carcinoma: the potential role of PET/MRI, The British journal of radiology 87(1036) (2014) 20130677.

[11] V. Murlidhar, N. Ramnath, S. Nagrath, R.M. Reddy, Optimizing the Detection of Circulating Markers to Aid in Early Lung Cancer Detection, Cancers (Basel) 8(7) (2016).

[12] S.R. Akkina, R.Y. Kim, C.L. Stucken, M.A. Pynnonen, C.R. Bradford, The current practice of open neck mass biopsy in the diagnosis of head and neck cancer: A retrospective cohort study, Laryngoscope investigative otolaryngology 4(1) (2019) 57-61.

[13] Head and neck cancer guide, https://headandneckcancerguide.org/adults/cancer-diagnosistreatments/diagnosis/biopsies/. 
[14] K.T. Palka, R.J. Slebos, C.H. Chung, Update on molecular diagnostic tests in head and neck cancer, Seminars in oncology 35(3) (2008) 198-210. [15] L. Keller, K. Pantel, Unravelling tumour heterogeneity by single-cell profiling of circulating tumour cells, Nature reviews. Cancer 19(10) (2019) 553-567.

[16] H. Schmidt, A. Kulasinghe, L. Kenny, C. Punyadeera, The development of a liquid biopsy for head and neck cancers, Oral oncology 61 (2016) 8-11.

[17] V. Kulasingam, E.P. Diamandis, Strategies for discovering novel cancer biomarkers through utilization of emerging technologies, Nature clinical practice. Oncology 5(10) (2008) 588-99.

[18] A. Almeida, D. Kolarich, The promise of protein glycosylation for personalised medicine, Biochim Biophys Acta 1860(8) (2016) 1583-95.

[19] K.W. Moremen, M. Tiemeyer, A.V. Nairn, Vertebrate protein glycosylation: diversity, synthesis and function, Nature reviews. Molecular cell biology 13(7) (2012) 448-62.

[20] S.S. Pinho, C.A. Reis, Glycosylation in cancer: mechanisms and clinical implications, Nature reviews. Cancer 15(9) (2015) 540-55.

[21] K.J. Colley, A. Varki, T. Kinoshita, Cellular Organization of Glycosylation, in: rd, A. Varki, R.D. Cummings, J.D. Esko, P. Stanley, G.W. Hart, M. Aebi, A.G. Darvill, T. Kinoshita, N.H. Packer, J.H. Prestegard, R.L. Schnaar, P.H. Seeberger (Eds.), Essentials of Glycobiology, Cold Spring Harbor Laboratory Press. Copyright 2015-2017 by The Consortium of Glycobiology Editors, La Jolla, California. All rights reserved., Cold Spring Harbor (NY), 2015, pp. 41-49.

[22] S.P.O.-G.G.I.V.A. Brockhausen I, Cummings RD, Esko JD, et al., editors. Essentials of Glycobiology [Internet]. 3rd edition. Cold Spring Harbor (NY): Cold Spring Harbor Laboratory Press; 2015-2017. Chapter 10. Available from: https://www.ncbi.nlm.nih.gov/books/NBK453030/ doi: 10.1101/glycobiology.3e.010, Essentials of Glycobiology [Internet]. 3rd edition.

[23] T.N. Stanley P, Aebi M. N-Glycans. 2017. In: Varki A, Cummings RD, Esko JD, et al., editors. Essentials of Glycobiology [Internet]. 3rd edition. Cold Spring Harbor (NY): Cold Spring Harbor Laboratory Press; 2015-2017. Chapter 9. Available from: https://www.ncbi.nlm.nih.gov/books/NBK453020/ doi: 10.1101/glycobiology.3e.009, Essentials of Glycobiology [Internet]. 3rd edition.

[24] C.R. Varki A, Esko JD, et al., , Essentials of Glycobiology [Internet]. 3rd edition. Cold Spring Harbor (NY): Cold Spring Harbor Laboratory Press; 2015-2017. .

[25] C. Reily, T.J. Stewart, M.B. Renfrow, J. Novak, Glycosylation in health and disease, Nat Rev Nephrol (2019).

[26] A.F. Nardy, L. Freire-de-Lima, C.G. Freire-de-Lima, A. Morrot, The Sweet Side of Immune Evasion: Role of Glycans in the Mechanisms of Cancer Progression, Frontiers in oncology 6 (2016) 54.

[27] P. Stanley, N. Taniguchi, M. Aebi, N-Glycans, in: rd, A. Varki, R.D. Cummings, J.D. Esko, P. Stanley, G.W. Hart, M. Aebi, A.G. Darvill, T. Kinoshita, N.H. Packer, J.H. Prestegard, R.L. Schnaar, P.H. Seeberger (Eds.), Essentials of Glycobiology, Cold Spring Harbor Laboratory Press, Cold Spring Harbor (NY), 2015, pp. 99-111.

[28] E.S. Trombetta, The contribution of $\mathrm{N}$-glycans and their processing in the endoplasmic reticulum to glycoprotein biosynthesis, Glycobiology 13(9) (2003) 77r-91r.

[29] N. Dean, Asparagine-linked glycosylation in the yeast Golgi, Biochim Biophys Acta 1426(2) (1999) 309-22.

[30] L. Oliveira-Ferrer, K. Legler, K. Milde-Langosch, Role of protein glycosylation in cancer metastasis, Seminars in cancer biology 44 (2017) 141-152.

[31] A. Vasconcelos-Dos-Santos, I.A. Oliveira, M.C. Lucena, N.R. Mantuano, S.A. Whelan, W.B. Dias, A.R. Todeschini, Biosynthetic Machinery Involved in Aberrant Glycosylation: Promising Targets for Developing of Drugs Against Cancer, Frontiers in oncology 5 (2015) 138.

[32] M. Thaysen-Andersen, V. Venkatakrishnan, I. Loke, C. Laurini, S. Diestel, B.L. Parker, N.H. Packer, Human neutrophils secrete bioactive paucimannosidic proteins from azurophilic granules into pathogen-infected sputum, J Biol Chem 290(14) (2015) 8789-802.

[33] I. Brockhausen, P. Stanley, O-GalNAc Glycans, in: rd, A. Varki, R.D. Cummings, J.D. Esko, P. Stanley, G.W. Hart, M. Aebi, A.G. Darvill, T. Kinoshita, N.H. Packer, J.H. Prestegard, R.L. Schnaar, P.H. Seeberger (Eds.), Essentials of Glycobiology, Cold Spring Harbor (NY), 2015, pp. 113-123. 
[34] P. Van den Steen, P.M. Rudd, R.A. Dwek, G. Opdenakker, Concepts and principles of O-linked glycosylation, Critical reviews in biochemistry and molecular biology 33(3) (1998) 151-208.

[35] K. Furukawa, Y. Ohkawa, Y. Yamauchi, K. Hamamura, Y. Ohmi, K. Furukawa, Fine tuning of cell signals by glycosylation, J Biochem 151(6) (2012) 573-8.

[36] B.N. Vajaria, P.S. Patel, Glycosylation: a hallmark of cancer?, Glycoconj J 34(2) (2017) 147156.

[37] I. Hauselmann, L. Borsig, Altered tumor-cell glycosylation promotes metastasis, Frontiers in oncology 4 (2014) 28.

[38] J. Munkley, D.J. Elliott, Hallmarks of glycosylation in cancer, Oncotarget 7(23) (2016) 3547889.

[39] M. Nita-Lazar, V. Noonan, I. Rebustini, J. Walker, A.S. Menko, M.A. Kukuruzinska, Overexpression of DPAGT1 leads to aberrant N-glycosylation of E-cadherin and cellular discohesion in oral cancer, Cancer research 69(14) (2009) 5673-5680.

[40] G. Liu, P.K. Sengupta, B. Jamal, H.Y. Yang, M.P. Bouchie, V. Lindner, X. Varelas, M.A.

Kukuruzinska, N-glycosylation induces the CTHRC1 protein and drives oral cancer cell migration, The Journal of biological chemistry 288(28) (2013) 20217-27.

[41] E. Miyoshi, M. Terao, Y. Kamada, Physiological roles of N-acetylglucosaminyltransferase $\mathrm{V}(\mathrm{GnT}-\mathrm{V})$ in mice, BMB reports 45(10) (2012) 554-9.

[42] J. Gu, N. Taniguchi, Potential of N-glycan in cell adhesion and migration as either a positive or negative regulator, Cell adhesion \& migration 2(4) (2008) 243-5.

[43] K.B. Chandler, C.E. Costello, N. Rahimi, Glycosylation in the Tumor Microenvironment: Implications for Tumor Angiogenesis and Metastasis, Cells 8(6) (2019).

[44] S.S. Pinho, J. Figueiredo, J. Cabral, S. Carvalho, J. Dourado, A. Magalhaes, F. Gartner, A.M. Mendonfa, T. Isaji, J. Gu, F. Carneiro, R. Seruca, N. Taniguchi, C.A. Reis, E-cadherin and adherensjunctions stability in gastric carcinoma: functional implications of glycosyltransferases involving Nglycan branching biosynthesis, N-acetylglucosaminyltransferases III and V, Biochim Biophys Acta 1830(3) (2013) 2690-700.

[45] S.D. Rosen, C.R. Bertozzi, The selectins and their ligands, Current opinion in cell biology 6(5) (1994) 663-73.

[46] A.W. Lambert, D.R. Pattabiraman, R.A. Weinberg, Emerging Biological Principles of Metastasis, Cell 168(4) (2017) 670-691.

[47] K.T. Yeung, J. Yang, Epithelial-mesenchymal transition in tumor metastasis, Mol Oncol 11(1) (2017) 28-39.

[48] X. Zhang, Y. Wang, Y. Qian, X. Wu, Z. Zhang, X. Liu, R. Zhao, L. Zhou, Y. Ruan, J. Xu, H. Liu, S. Ren, C. Xu, J. Gu, Discovery of specific metastasis-related N-glycan alterations in epithelial ovarian cancer based on quantitative glycomics, PloS one 9(2) (2014) e87978.

[49] I.O. Potapenko, V.D. Haakensen, T. Luders, A. Helland, I. Bukholm, T. Sorlie, V.N. Kristensen, O.C. Lingjaerde, A.L. Borresen-Dale, Glycan gene expression signatures in normal and malignant breast tissue; possible role in diagnosis and progression, Mol Oncol 4(2) (2010) 98-118.

[50] A.T. Nguyen, J. Chia, M. Ros, K.M. Hui, F. Saltel, F. Bard, Organelle Specific O-Glycosylation Drives MMP14 Activation, Tumor Growth, and Metastasis, Cancer Cell 32(5) (2017) 639-653.e6.

[51] H. Läubli, L. Borsig, Altered Cell Adhesion and Glycosylation Promote Cancer Immune Suppression and Metastasis, Frontiers in Immunology 10(2120) (2019).

[52] X. Yu, Q. Wu, L. Wang, Y. Zhao, Q. Zhang, Q. Meng, Pawan, S. Wang, Silencing of ST6GalNAc I suppresses the proliferation, migration and invasion of hepatocarcinoma cells through PI3K/AKT/NF-kappaB pathway, Tumour Biol 37(9) (2016) 12213-12221.

[53] S.K. More, N. Srinivasan, S. Budnar, S.M. Bane, A. Upadhya, R.A. Thorat, A.D. Ingle, S.V. Chiplunkar, R.D. Kalraiya, N-glycans and metastasis in galectin-3 transgenic mice, Biochemical and biophysical research communications 460(2) (2015) 302-7.

[54] P.K. Sengupta, M.P. Bouchie, M. Nita-Lazar, H.Y. Yang, M.A. Kukuruzinska, Coordinate regulation of N-glycosylation gene DPAGT1, canonical Wnt signaling and E-cadherin adhesion, Journal of cell science 126(Pt 2) (2013) 484-96.

[55] Y. Kariya, J. Gu, N-glycosylation of ss4 integrin controls the adhesion and motility of keratinocytes, PloS one 6(11) (2011) e27084. 
[56] Y. Kariya, R. Kato, S. Itoh, T. Fukuda, Y. Shibukawa, N. Sanzen, K. Sekiguchi, Y. Wada, N. Kawasaki, J. Gu, N-Glycosylation of laminin-332 regulates its biological functions. A novel function of the bisecting GlcNAc, J Biol Chem 283(48) (2008) 33036-45. [57] C.M. Wilson, S. High, Ribophorin I acts as a substrate-specific facilitator of N-glycosylation, Journal of cell science 120(Pt 4) (2007) 648-57.

[58] M.A. Guervos, C.A. Marcos, M. Hermsen, A.S. Nuno, C. Suarez, J.L. Llorente, Deletions of N33, STK11 and TP53 are involved in the development of lymph node metastasis in larynx and pharynx carcinomas, Cellular oncology : the official journal of the International Society for Cellular Oncology 29(4) (2007) 327-34.

[59] K. Milde-Langosch, T. Karn, M. Schmidt, C. zu Eulenburg, L. Oliveira-Ferrer, R.M. Wirtz, U. Schumacher, I. Witzel, D. Schutze, V. Muller, Prognostic relevance of glycosylation-associated genes in breast cancer, Breast Cancer Res Treat 145(2) (2014) 295-305.

[60] J.J. Park, M. Lee, Increasing the alpha 2, 6 sialylation of glycoproteins may contribute to metastatic spread and therapeutic resistance in colorectal cancer, Gut and liver 7(6) (2013) 629-41. [61] C.Y. Chen, Y.H. Jan, Y.H. Juan, C.J. Yang, M.S. Huang, C.J. Yu, P.C. Yang, M. Hsiao, T.L. Hsu, C.H. Wong, Fucosyltransferase 8 as a functional regulator of nonsmall cell lung cancer, Proceedings of the National Academy of Sciences of the United States of America 110(2) (2013) 6305 .

[62] H. Ozaki, H. Matsuzaki, H. Ando, H. Kaji, H. Nakanishi, Y. Ikehara, H. Narimatsu, Enhancement of metastatic ability by ectopic expression of ST6GalNAcI on a gastric cancer cell line in a mouse model, Clin Exp Metastasis 29(3) (2012) 229-38.

[63] C.F. Bian, Y. Zhang, H. Sun, D.F. Li, D.C. Wang, Structural basis for distinct binding properties of the human galectins to Thomsen-Friedenreich antigen, PloS one 6(9) (2011) e25007.

[64] C.H. Chou, M.J. Huang, C.H. Chen, M.K. Shyu, J. Huang, J.S. Hung, C.S. Huang, M.C. Huang, Up-regulation of C1GALT1 promotes breast cancer cell growth through MUC1-C signaling pathway, Oncotarget 6(8) (2015) 6123-35.

[65] W.D. Hanley, M.M. Burdick, K. Konstantopoulos, R. Sackstein, CD44 on LS174T colon carcinoma cells possesses E-selectin ligand activity, Cancer Res 65(13) (2005) 5812-7.

[66] T. Liu, S. Zhang, J. Chen, K. Jiang, Q. Zhang, K. Guo, Y. Liu, The transcriptional profiling of glycogenes associated with hepatocellular carcinoma metastasis, PloS one 9(9) (2014) e107941. [67] C.H. Tsai, S.F. Tzeng, T.K. Chao, C.Y. Tsai, Y.C. Yang, M.T. Lee, J.J. Hwang, Y.C. Chou, M.H. Tsai, T.L. Cha, P.W. Hsiao, Metastatic Progression of Prostate Cancer Is Mediated by Autonomous Binding of Galectin-4-O-Glycan to Cancer Cells, Cancer Res 76(19) (2016) 5756-5767. [68] M.J. Huang, R.H. Hu, C.H. Chou, C.L. Hsu, Y.W. Liu, J. Huang, J.S. Hung, I.R. Lai, H.F. Juan, S.L. Yu, Y.M. Wu, M.C. Huang, Knockdown of GALNT1 suppresses malignant phenotype of hepatocellular carcinoma by suppressing EGFR signaling, Oncotarget 6(8) (2015) 5650-65. [69] M. Perez-Garay, B. Arteta, E. Llop, L. Cobler, L. Pages, R. Ortiz, M.J. Ferri, C. de Bolos, J. Figueras, R. de Llorens, F. Vidal-Vanaclocha, R. Peracaula, alpha2,3-Sialyltransferase ST3Gal IV promotes migration and metastasis in pancreatic adenocarcinoma cells and tends to be highly expressed in pancreatic adenocarcinoma tissues, The international journal of biochemistry \& cell biology 45(8) (2013) 1748-57.

[70] E. El Rassy, H. Khaled, N. Pavlidis, Liquid biopsy: a new diagnostic, predictive and prognostic window in cancers of unknown primary, European journal of cancer 105 (2018) 28-32.

[71] K. Pantel, C. Alix-Panabieres, Liquid biopsy and minimal residual disease - latest advances and implications for cure, Nat Rev Clin Oncol (2019).

[72] P. Ghatalia, C.H. Smith, A. Winer, J. Gou, L.A. Kiedrowski, M. Slifker, P.D. Saltzberg, N. Bubes, F.M. Anari, V. Kasireddy, A. Varshavsky, Y. Liu, E.A. Ross, W.S. El-Deiry, Clinical Utilization Pattern of Liquid Biopsies (LB) to Detect Actionable Driver Mutations, Guide Treatment Decisions and Monitor Disease Burden During Treatment of 33 Metastatic Colorectal Cancer (mCRC) Patients (pts) at a Fox Chase Cancer Center GI Oncology Subspecialty Clinic, Frontiers in oncology 8 (2018) 652.

[73] S. Mazumder, S. Datta, J.G. Ray, K. Chaudhuri, R. Chatterjee, Liquid biopsy: miRNA as a potential biomarker in oral cancer, Cancer epidemiology 58 (2019) 137-145.

[74] A. Jung, T. Kirchner, Liquid Biopsy in Tumor Genetic Diagnosis, Deutsches Arzteblatt international 115(10) (2018) 169-174. 
[75] M. Neves, R. Azevedo, L. Lima, M.I. Oliveira, A. Peixoto, D. Ferreira, J. Soares, E. Fernandes, C. Gaiteiro, C. Palmeira, S. Cotton, S. Mereiter, D. Campos, L.P. Afonso, R. Ribeiro, A. Fraga, A. Tavares, H. Mansinho, E. Monteiro, P.A. Videira, P.P. Freitas, C.A. Reis, L.L. Santos, L. Dieguez, J.A. Ferreira, Exploring sialyl-Tn expression in microfluidic-isolated circulating tumour cells: A novel biomarker and an analytical tool for precision oncology applications, New biotechnology 49 (2019) 77-87.

[76] E.S. Williams, V. Rodriguez-Bravo, U. Chippada-Venkata, J. De Ia Iglesia-Vicente, Y. Gong, M. Galsky, W. Oh, C. Cordon-Cardo, J. Domingo-Domenech, Generation of Prostate Cancer Patient Derived Xenograft Models from Circulating Tumor Cells, Journal of visualized experiments : JoVE (105) (2015) 53182.

[77] D.C. Danila, M. Fleisher, H.I. Scher, Circulating tumor cells as biomarkers in prostate cancer, Clin Cancer Res 17(12) (2011) 3903-12.

[78] D.C. Danila, G. Heller, G.A. Gignac, R. Gonzalez-Espinoza, A. Anand, E. Tanaka, H. Lilja, L. Schwartz, S. Larson, M. Fleisher, H.I. Scher, Circulating tumor cell number and prognosis in progressive castration-resistant prostate cancer, Clin Cancer Res 13(23) (2007) 7053-8.

[79] J.F. Chen, H. Ho, J. Lichterman, Y.T. Lu, Y. Zhang, M.A. Garcia, S.F. Chen, A.J. Liang, E. Hodara, H.E. Zhau, S. Hou, R.S. Ahmed, D.J. Luthringer, J. Huang, K.C. Li, L.W. Chung, Z. Ke, H.R. Tseng, E.M. Posadas, Subclassification of prostate cancer circulating tumor cells by nuclear size reveals very small nuclear circulating tumor cells in patients with visceral metastases, Cancer 121(18) (2015) 3240-51.

[80] M.C. Liu, P.G. Shields, R.D. Warren, P. Cohen, M. Wilkinson, Y.L. Ottaviano, S.B. Rao, J. EngWong, F. Seillier-Moiseiwitsch, A.M. Noone, C. Isaacs, Circulating tumor cells: a useful predictor of treatment efficacy in metastatic breast cancer, J Clin Oncol 27(31) (2009) 5153-9.

[81] D.F. Hayes, C. Paoletti, Circulating tumour cells: insights into tumour heterogeneity, Journal of internal medicine 274(2) (2013) 137-43.

[82] G. Attard, J.F. Swennenhuis, D. Olmos, A.H. Reid, E. Vickers, R. A'Hern, R. Levink, F. Coumans, J. Moreira, R. Riisnaes, N.B. Oommen, G. Hawche, C. Jameson, E. Thompson, R. Sipkema, C.P. Carden, C. Parker, D. Dearnaley, S.B. Kaye, C.S. Cooper, A. Molina, M.E. Cox, L.W. Terstappen, J.S. de Bono, Characterization of ERG, AR and PTEN gene status in circulating tumor cells from patients with castration-resistant prostate cancer, Cancer Res 69(7) (2009) 2912-8. [83] L. Lima, M. Neves, M.I. Oliveira, L. Dieguez, R. Freitas, R. Azevedo, C. Gaiteiro, J. Soares, D. Ferreira, A. Peixoto, E. Fernandes, D. Montezuma, A. Tavares, R. Ribeiro, A. Castro, M. Oliveira, A. Fraga, C.A. Reis, L.L. Santos, J.A. Ferreira, Sialyl-Tn identifies muscle-invasive bladder cancer basal and luminal subtypes facing decreased survival, being expressed by circulating tumor cells and metastases, Urologic oncology 35(12) (2017) 675.e1-675.e8.

[84] S. Gkountela, F. Castro-Giner, B.M. Szczerba, M. Vetter, J. Landin, R. Scherrer, I. Krol, M.C. Scheidmann, C. Beisel, C.U. Stirnimann, C. Kurzeder, V. Heinzelmann-Schwarz, C. Rochlitz, W.P. Weber, N. Aceto, Circulating Tumor Cell Clustering Shapes DNA Methylation to Enable Metastasis Seeding, Cell 176(1-2) (2019) 98-112.e14.

[85] J.A. Denis, J.M. Lacorte, Detection of RAS mutations in circulating tumor cells: applications in colorectal cancer and prospects, Annales de biologie clinique 75(6) (2017) 607-618.

[86] J.A. Shaw, D.S. Guttery, A. Hills, D. Fernandez-Garcia, K. Page, B.M. Rosales, K.S. Goddard, R.K. Hastings, J. Luo, O. Ogle, L. Woodley, S. Ali, J. Stebbing, R.C. Coombes, Mutation Analysis of Cell-Free DNA and Single Circulating Tumor Cells in Metastatic Breast Cancer Patients with High Circulating Tumor Cell Counts, Clin Cancer Res 23(1) (2017) 88-96.

[87] S. Sharma, R. Zhuang, M. Long, M. Pavlovic, Y. Kang, A. Ilyas, W. Asghar, Circulating tumor cell isolation, culture, and downstream molecular analysis, Biotechnology advances 36(4) (2018) 1063-1078.

[88] L. Cabel, C. Proudhon, H. Gortais, D. Loirat, F. Coussy, J.Y. Pierga, F.C. Bidard, Circulating tumor cells: clinical validity and utility, International journal of clinical oncology 22(3) (2017) 421430.

[89] K.S. Lau, J.W. Dennis, N-Glycans in cancer progression, Glycobiology 18(10) (2008) 750-60. [90] X. Huang, T. Liu, Q. Wang, W. Zhu, H. Meng, L. Guo, T. Wei, J. Zhang, Inhibition of Nacetylglucosaminyltransferase $\mathrm{V}$ enhances the cetuximab-induced radiosensitivity of nasopharyngeal carcinoma cells likely through EGFR N-glycan alterations, Glycobiology (2017). 

radioresistance of human nasopharyngeal carcinoma cells by alteration $\beta 1,6-$ GlcNAc branched Nglycans, Int J Clin Exp Pathol 8(9) (2015) 9901-11. [92] N. Beauchemin, A. Arabzadeh, Carcinoembryonic antigen-related cell adhesion molecules (CEACAMs) in cancer progression and metastasis, Cancer metastasis reviews 32(3-4) (2013) 643-71. [93] W.F. Chiang, T.M. Cheng, C.C. Chang, S.H. Pan, C.A. Changou, T.H. Chang, K.H. Lee, S.Y. Wu, Y.F. Chen, K.H. Chuang, D.B. Shieh, Y.L. Chen, C.C. Tu, W.L. Tsui, M.H. Wu, Carcinoembryonic antigen-related cell adhesion molecule 6 (CEACAM6) promotes EGF receptor signaling of oral squamous cell carcinoma metastasis via the complex $\mathrm{N}$-glycosylation, Oncogene 37(1) (2018) 116-127.

[94] Z.Q. Wang, M. Bachvarova, C. Morin, M. Plante, J. Gregoire, M.C. Renaud, A. Sebastianelli, D. Bachvarov, Role of the polypeptide $\mathrm{N}$-acetylgalactosaminyltransferase 3 in ovarian cancer progression: possible implications in abnormal mucin O-glycosylation, Oncotarget 5(2) (2014) 54460.

[95] M.R. Hussain, D.C. Hoessli, M. Fang, N-acetylgalactosaminyltransferases in cancer, Oncotarget 7(33) (2016) 54067-54081.

[96] I. Brockhausen, Mucin-type O-glycans in human colon and breast cancer: glycodynamics and functions, EMBO reports 7(6) (2006) 599-604.

[97] M.C. Lin, P.H. Chien, H.Y. Wu, S.T. Chen, H.F. Juan, P.J. Lou, M.C. Huang, C1GALT1 predicts poor prognosis and is a potential therapeutic target in head and neck cancer, Oncogene (2018).

[98] X. Dong, Z. Luo, Y. Wang, L. Meng, Q. Duan, L. Qiu, F. Peng, L. Shen, Altered O-glycosylation is associated with inherent radioresistance and malignancy of human laryngeal carcinoma, Experimental cell research 362(2) (2018) 302-310.

[99] M.C. Lin, M.J. Huang, C.H. Liu, T.L. Yang, M.C. Huang, GALNT2 enhances migration and invasion of oral squamous cell carcinoma by regulating EGFR glycosylation and activity, Oral oncology 50(5) (2014) 478-84.

[100] Y. Harada, H. Izumi, H. Noguchi, A. Kuma, Y. Kawatsu, T. Kimura, S. Kitada, H. Uramoto, K.Y. Wang, Y. Sasaguri, H. Hijioka, A. Miyawaki, R. Oya, T. Nakayama, K. Kohno, S. Yamada, Strong expression of polypeptide $\mathrm{N}$-acetylgalactosaminyltransferase 3 independently predicts shortened disease-free survival in patients with early stage oral squamous cell carcinoma, Tumour Biol 37(1) (2016) 1357-68.

[101] I. Wiest, C. Alexiou, K. Friese, P. Betz, J. Tubel, S. Goletz, D. Dian, U. Jeschke, Expression of the Tumor-associated Mucin 1 Epitope Analyzed with the Humanized PankoMab-GEX Antibody in Malignant and Normal Tissues of the Head and Neck, Anticancer research 36(6) (2016) 3179-84. [102] T. Miyagi, K. Takahashi, K. Hata, K. Shiozaki, K. Yamaguchi, Sialidase significance for cancer progression, Glycoconj J 29(8-9) (2012) 567-77.

[103] A. Guillot, M. Dauchez, N. Belloy, J. Jonquet, L. Duca, B. Romier, P. Maurice, L. Debelle, L. Martiny, V. Durlach, S. Baud, S. Blaise, Impact of sialic acids on the molecular dynamic of biantennary and tri-antennary glycans, Scientific reports 6 (2016) 35666.

[104] K. Shiga, K. Takahashi, I. Sato, K. Kato, S. Saijo, S. Moriya, M. Hosono, T. Miyagi, Upregulation of sialidase NEU3 in head and neck squamous cell carcinoma associated with lymph node metastasis, Cancer Sci 106(11) (2015) 1544-53.

[105] J. Baeten, A. Suresh, A. Johnson, K. Patel, M. Kuriakose, A. Flynn, D. Kademani, Molecular imaging of oral premalignant and malignant lesions using fluorescently labeled lectins, Transl Oncol 7(2) (2014) 213-20.

[106] M. Borzym-Kluczyk, I. Radziejewska, M. Cechowska-Pasko, Glycosylation of proteins in healthy and neoplastic human salivary glands - a preliminary study, Clinical chemistry and laboratory medicine 49(5) (2011) 885-9.

[107] K. Flem-Karlsen, O. Fodstad, M. Tan, C.E. Nunes-Xavier, B7-H3 in Cancer - Beyond Immune Regulation, Trends in cancer 4(6) (2018) 401-404.

[108] J.T. Chen, C.H. Chen, K.L. Ku, M. Hsiao, C.P. Chiang, T.L. Hsu, M.H. Chen, C.H. Wong, Glycoprotein B7-H3 overexpression and aberrant glycosylation in oral cancer and immune response, Proceedings of the National Academy of Sciences of the United States of America 112(42) (2015) 13057-62. 

Mele, F. Papaccio, R. Montella, G. Papaccio, S. Papagerakis, Increased fucosylation has a pivotal role in invasive and metastatic properties of head and neck cancer stem cells, Oncotarget 6(1) (2015) 71 84.

[110] N. Höti, T.S. Lih, J. Pan, Y. Zhou, G. Yang, A. Deng, L. Chen, M. Dong, R.B. Yang, C.F. Tu, M.C. Haffner, Q. Kay Li, H. Zhang, A Comprehensive Analysis of FUT8 Overexpressing Prostate Cancer Cells Reveals the Role of EGFR in Castration Resistance, Cancers 12(2) (2020).

[111] X. Wang, J. Gu, H. Ihara, E. Miyoshi, K. Honke, N. Taniguchi, Core fucosylation regulates epidermal growth factor receptor-mediated intracellular signaling, The Journal of biological chemistry 281(5) (2006) 2572-7.

[112] W.L. Lin, Y.S. Lin, G.Y. Shi, C.F. Chang, H.L. Wu, Lewisy promotes migration of oral cancer cells by glycosylation of epidermal growth factor receptor, PloS one 10(3) (2015) e0120162.

[113] X. Wu, J.S. Rush, D. Karaoglu, D. Krasnewich, M.S. Lubinsky, C.J. Waechter, R. Gilmore, H.H. Freeze, Deficiency of UDP-GlcNAc:Dolichol Phosphate N-Acetylglucosamine-1 Phosphate Transferase (DPAGT1) causes a novel congenital disorder of Glycosylation Type Ij, Human mutation 22(2) (2003) 144-50.

[114] B.G. Ng, H.R. Underhill, L. Palm, P. Bengtson, J.M. Rozet, S. Gerber, A. Munnich, X. Zanlonghi, C.A. Stevens, M. Kircher, D.A. Nickerson, K.J. Buckingham, K.D. Josephson, J. Shendure, M.J. Bamshad, G. University of Washington Center for Mendelian, H.H. Freeze, E.A. Eklund, DPAGT1 Deficiency with Encephalopathy (DPAGT1-CDG): Clinical and Genetic Description of 11 New Patients, JIMD Rep 44 (2019) 85-92.

[115] M. Nita-Lazar, V. Noonan, I. Rebustini, J. Walker, A.S. Menko, M.A. Kukuruzinska, Overexpression of DPAGT1 leads to aberrant N-glycosylation of E-cadherin and cellular discohesion in oral cancer, Cancer research 69(14) (2009) 5673-80.

[116] B. Jamal, P.K. Sengupta, Z.N. Gao, M. Nita-Lazar, B. Amin, S. Jalisi, M.P. Bouchie, M.A. Kukuruzinska, Aberrant amplification of the crosstalk between canonical Wnt signaling and Nglycosylation gene DPAGT1 promotes oral cancer, Oral oncology 48(6) (2012) 523-9.

[117] S.Y. Guu, T.H. Lin, S.C. Chang, R.J. Wang, L.Y. Hung, P.J. Fang, W.C. Tang, P. Yu, C.F. Chang, Serum N-glycome characterization and anti-carbohydrate antibody profiling in oral squamous cell carcinoma patients, PloS one 12(6) (2017) e0178927.

[118] E. Toth, K. Vekey, O. Ozohanics, A. Jeko, I. Dominczyk, P. Widlak, L. Drahos, Changes of protein glycosylation in the course of radiotherapy, Journal of pharmaceutical and biomedical analysis 118 (2016) 380-386.

[119] B.N. Vajaria, K.R. Patel, R. Begum, J.B. Patel, F.D. Shah, G.M. Joshi, P.S. Patel, Salivary glyco-sialylation changes monitors oral carcinogenesis, Glycoconj J 31(9) (2014) 649-59.

[120] B.N. Vajaria, K.R. Patel, R. Begum, F.D. Shah, J.B. Patel, S.N. Shukla, P.S. Patel, Evaluation of serum and salivary total sialic acid and alpha-1-fucosidase in patients with oral precancerous conditions and oral cancer, Oral surgery, oral medicine, oral pathology and oral radiology 115(6) (2013) 764-71.

[121] N. Dhakar, M. Astekar, M. Jain, S. Saawarn, N. Saawarn, Total sialic acid, total protein and total sugar levels in serum and saliva of oral squamous cell carcinoma patients: A case control study, Dental research journal 10(3) (2013) 343-7.

[122] V. Chaudhari, G.L. Pradeep, N. Prakash, A.M. Mahajan, Estimation of salivary sialic acid in oral premalignancy and oral squamous cell carcinoma, Contemporary clinical dentistry 7(4) (2016) 451-456.

[123] N. Sinevici, S. Mittermayr, G.P. Davey, J. Bones, J. O'Sullivan, Salivary N-glycosylation as a biomarker of oral cancer: A pilot study, Glycobiology 29(10) (2019) 726-734.

[124] N.W. Johnson, D. Malamud, D. Reznik, D.J. Speicher, J. Phelan, Mucosal fluids and biomarkers of clinical disease: workshop 3B, Advances in dental research 23(1) (2011) 137-41. [125] D. Zhang, L. Zhao, P. Zhou, H. Ma, F. Huang, M. Jin, X. Dai, X. Zheng, S. Huang, T. Zhang, Circulating tumor microemboli (CTM) and vimentin+ circulating tumor cells (CTCs) detected by a size-based platform predict worse prognosis in advanced colorectal cancer patients during chemotherapy, Cancer cell international 17 (2017) 6.

[126] H. Cho, J. Kim, H. Song, K.Y. Sohn, M. Jeon, K.H. Han, Microfluidic technologies for circulating tumor cell isolation, The Analyst 143(13) (2018) 2936-2970. 
[127] A. Kulasinghe, C. Perry, L. Jovanovic, C. Nelson, C. Punyadeera, Circulating tumour cells in metastatic head and neck cancers, International journal of cancer. Journal international du cancer 136(11) (2015) 2515-23.

[128] H. Esmaeilsabzali, T.V. Beischlag, M.E. Cox, A.M. Parameswaran, E.J. Park, Detection and isolation of circulating tumor cells: principles and methods, Biotechnology advances 31(7) (2013) 1063-84.

[129] T. Lange, T.R. Samatov, A.G. Tonevitsky, U. Schumacher, Importance of altered glycoproteinbound $\mathrm{N}$ - and O-glycans for epithelial-to-mesenchymal transition and adhesion of cancer cells, Carbohydrate research 389 (2014) 39-45. [130] W. Zhang, Z. Li, Z. Wang, C. Yue, H. Zheng, R. Li, M. Zhou, Z. Hu, Z. Wei, Q. Li, Generation of a monoclonal antibody recognizing the heavily glycosylated CD45 protein and its application on identifying circulating tumor cells, PloS one 13(2) (2018) e0192506.

461 [131] D. Wang, X. Liu, B. Hsieh, R. Bruce, G. Somlo, J. Huang, L. Sambucetti, Exploring Glycan 462 Markers for Immunotyping and Precision-targeting of Breast Circulating Tumor Cells, Archives of medical research 46(8) (2015) 642-50.

[132] A.C. Kolbl, R.A. Hiller, M. Ilmer, F. Liesche, S. Heublein, L. Schroder, S. Hutter, K. Friese, U. Jeschke, U. Andergassen, Glycosyltransferases as marker genes for the quantitative polymerase chain reaction-based detection of circulating tumour cells from blood samples of patients with breast cancer undergoing adjuvant therapy, Molecular medicine reports 12(2) (2015) 2933-8.

[133] R. Saldova, J.M. Reuben, U.M. Abd Hamid, P.M. Rudd, M. Cristofanilli, Levels of specific serum N-glycans identify breast cancer patients with higher circulating tumor cell counts, Annals of oncology : official journal of the European Society for Medical Oncology 22(5) (2011) 1113-9. [134] A. Varki, R. Kannagi, B. Toole, P. Stanley, Glycosylation Changes in Cancer, in: rd, A. Varki, R.D. Cummings, J.D. Esko, P. Stanley, G.W. Hart, M. Aebi, A.G. Darvill, T. Kinoshita, N.H. Packer, J.H. Prestegard, R.L. Schnaar, P.H. Seeberger (Eds.), Essentials of Glycobiology, Cold Spring Harbor (NY), Cold Spring Harbor (NY), 2015, pp. 597-609. 